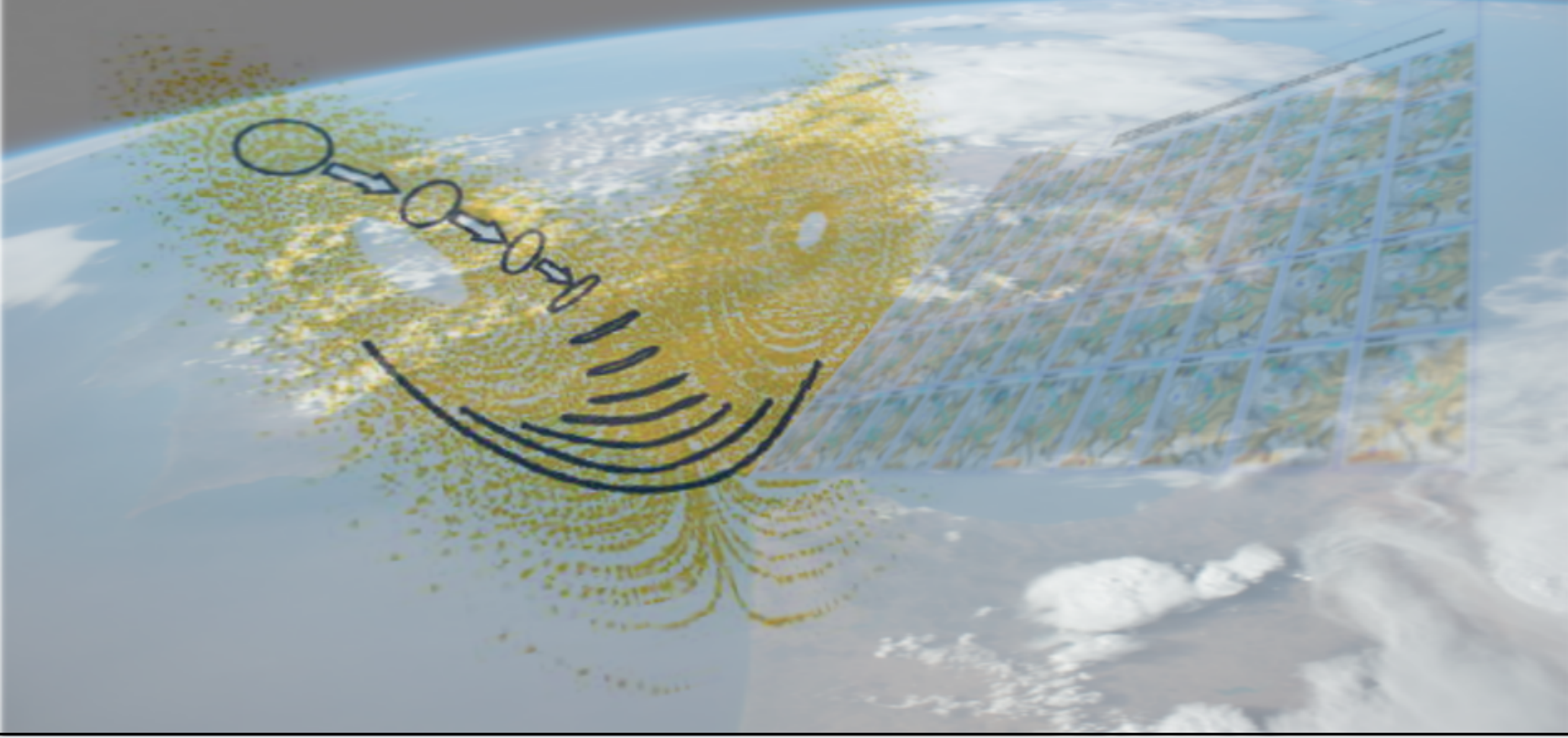

\title{
Sistemas de predicción por conjuntos (SPC)
}

\author{
Carlos Santos Burguete \\ Centro Nacional de Predicción (CNP), Agencia Estatal de Meteorología (AEMET)
}

Ningún hombre es una isla, algo completo en sí mismo; todo hombre es un fragmento del continente, una parte de un conjunto.

Devociones para Ocasiones Emergentes - JOHN DONNE

Describimos la atmósfera como un sistema dinámico altamente no lineal. Por su naturaleza, este tipo de sistemas es sensible a las condiciones iniciales, además de serlo a la formulación del modelo, lo que impone un límite físico a su predecibilidad: la atmósfera puede predecirse con cierta exactitud solo hasta un cierto horizonte de predicción en el tiempo. El meteorólogo E. N. LORENZ, en los años 1960 estimó, desde un punto de vista teórico, unos márgenes para ese límite entre 2 y 3 semanas. Asumiendo esta limitación natural de las predicciones deterministas, el único modo de afrontar el reto de hacer predicciones de calidad es introducir la probabilidad de forma natural en los sistemas de predicción. El problema de la predecibilidad se articula entonces en términos de describir el estado atmosférico mediante una función de densidad de probabilidad (en inglés probability density function, PDF) adecuada. De ese modo podremos, además de describir la evolución del estado atmosférico, describir las incertidumbres asociadas a esa evolución. Los sistemas de predicción por conjuntos son la primera aproximación técnicamente plausible con la que se ha realizado esta idea. En este capítulo exponemos los fundamentos básicos de estos sistemas.

Palabras clave: sistemas de predicción por conjuntos, ensemble, predecibilidad, escenarios, incertidumbre en la predicción atmosférica. 


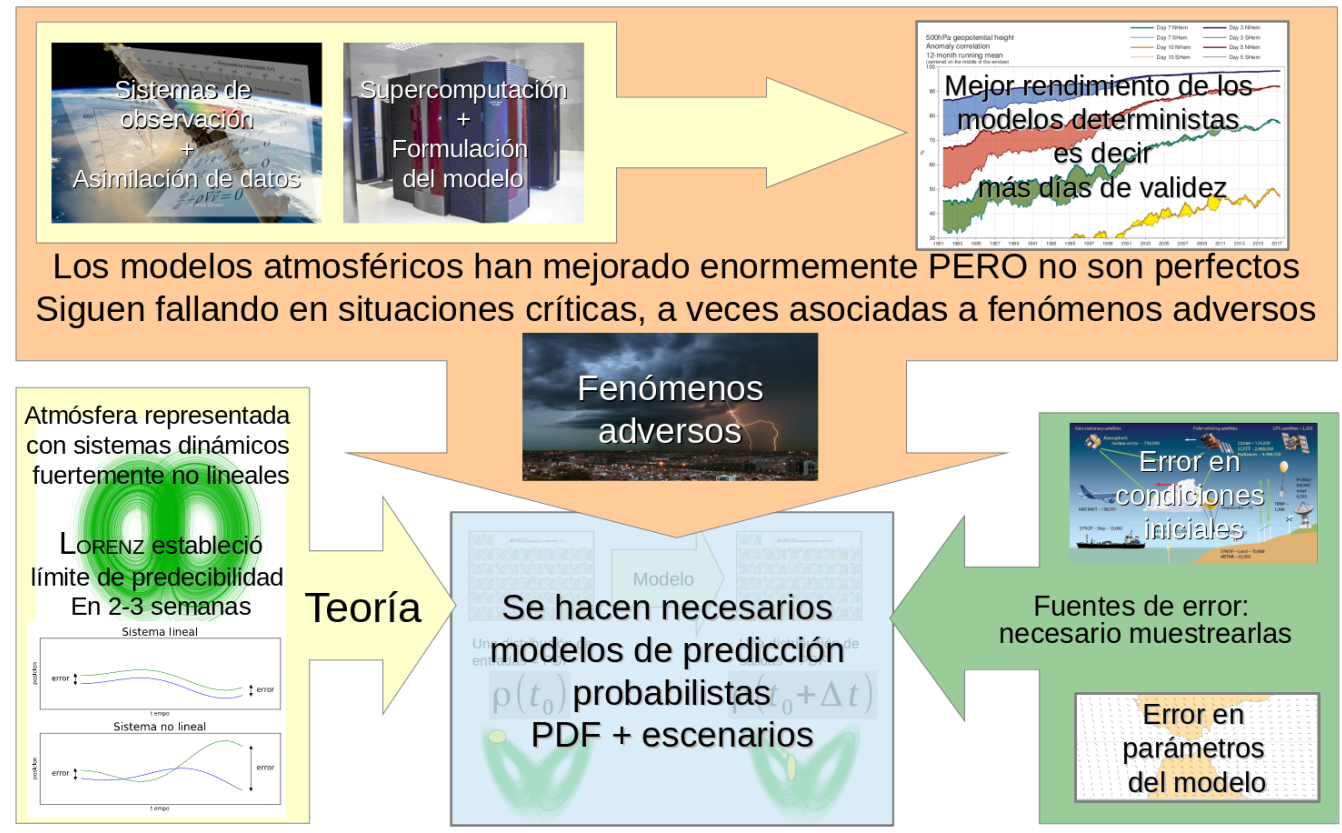

Figura 13.1: Esquema que resume contenidos previos de otros capítulos, mostrando la necesidad de los sistemas de predicción probabilistas (ver texto).

\subsection{Necesidad}

Como ya hemos descrito en capítulos anteriores (capítulos 5 en la página 49 y 12 en la página 155) los modelos atmosféricos deterministas revolucionaron el mundo de la predicción del tiempo y han mejorado enormemente en las últimas décadas. Los sistemas de observación, en particular los satélites meteorológicos (cap. 7 en la página 83), han supuesto un avance crítico, así como los métodos de asimilación (sección 10.3 en la página 133) de los datos correspondientes en los modelos. La formulación del modelo puede ser, a su vez, cada vez más completa y detallada gracias, en parte, a las mejorías vertiginosas en supercomputación (capítulo 11 en la página 145) que permiten aumentar la resolución espacial y temporal en la descripción de los fenómenos meteorológicos en el modelo. Las medidas objetivas de calidad determinista de los modelos muestran esta mejoría de muchos modos, ya sea con medidas cuantitativas de rendimiento como en su equivalente en términos de periodo de validez de las predicciones (capítulo 15 en la página 207).

Sin embargo, estos modelos todavía están lejos de ser perfectos y siguen fallando en algunas situaciones meteorológicas importantes, como son por ejemplo aquellas en las que la convección juega un papel crucial y, en general, las relacionadas con fenómenos extremos o fenómenos adversos. Hay un número de días del año en que el predictor del tiempo no puede dar al modelo la misma confianza que normalmente, porque es inconsistente, sesgado, en una palabra, poco de fiar. ¿Por qué?

Se requiere investigar la fuentes de error e incertidumbres, profundizando en la teoría subyacente a la dinámica y la modelización. Respecto a las fuentes de error, hemos visto también en capítulos precedentes que hay dos fuentes principales de error e incertidumbre en los modelos: (i) en las condiciones iniciales, debido a la propia imperfección de los sistemas de observación y de asimilación de datos y (ii) en la formulación del propio modelo, tanto en la dinámica como en la parametrizaciones. En lo tocante a la teoría, hemos visto cómo el carácter fuertemente no lineal de los sistemas dinámicos con los que describimos la atmósfera los hace hipersensibles a pequeñas variaciones en las condiciones iniciales, lo que a la postre impone un límite físico a su predecibilidad. El meteorólogo EDWARD N. LORENZ estudió cómo este límite variaba con la escala espaciotemporal y estimó, para escalas sinópticas, un límite aproximado de 2-3 semanas (para escalas convectivas sería de 3-6 horas). Se hacen necesarios, por tanto, sistemas de predicción probabilistas. Estas ideas quedan sintetizadas en la Figura 13.1.

¿Qué se hacía antes, cuando no se contaba con la posibilidad de desarrollar sistemas de predicción probabilistas? 


\section{2 ¿Qué se hacía antes de los SPC?}

Antes de la aparición, en los años 90 (en la Agencia Estatal de Meteorología (AEMET) empezaron en 1998 y, sistemáticamente, en 2 000), de los sistema(s) de predicción por conjuntos (SPC) como herramienta para la predicción, en los centros de predicción operativa se seguían estrategias clásicas para tener en cuenta, de un modo u otro, las incertidumbres en las predicciones.

\subsubsection{Consistencia entre pasadas}

Una comprobación habitual, vigente aún hoy y bastante útil aunque no exenta de cierta subjetividad, es la consistencia entre pasadas sucesivas del mismo modelo atmosférico. ¿En qué consiste esta comprobación? Imaginemos que hoy es día $\mathrm{D}$ y estamos interesados en hacer una predicción para el día D+2 a las 12 UTC. Disponemos de pasadas de las 00 UTC y las 12 UTC de un modelo atmosférico, por ejemplo el ECHRES (sec. 19.2 en la página 291), modelo determinista del European Centre for Medium-range Weather Forecasts -Centro Europeo de Predicción a Plazo Medio(ECMWF), lo que se simplifica habitualmente en jerga de centro de predicción como «pasadas de cero y doce». Para hacer la predicción del día D+2 a las 12 UTC podemos usar la pasada de hoy día D a las 00 UTC (habitualmente disponible en la práctica a las 07 UTC), alcance de T+60. Podemos comprobar también qué decía la pasada inmediatamente anterior para ese mismo momento. Es decir, la pasada de ayer día D-1 de las 12 UTC, alcance de T+72 h:

Pasada D de 00 UTC + alcance 60 h = válido D+2 a las 12 UTC

Pasada D-1 de 12 UTC + alcance 72 h = válido D+2 a las 12 UTC

En principio, cuanto más reciente es la pasada más fiable es la salida del modelo, pues las observaciones con las que está inicializado son más recientes. Pero no necesariamente y no siempre es mejor la última pasada. En ocasiones (podemos hablar de un $10 \%$ de los casos) la pasada anterior da una mejor aproximación para la atmósfera, por diversas razones (sec. 15.1.1 en la página 208). En cualquier caso, la consistencia entre pasadas sucesivas es un indicativo, subjetivo pero útil, de fiabilidad de las salidas del modelo. Esta comprobación tiene sentido y encaja con la idea, también subjetiva hasta cierto punto, de la fiabilidad que podemos otorgar al modelo en los diversos tipos de situación. Si se nos presenta una atmósfera estable, e.g. predominio de altas presiones, las sucesivas pasadas van a parecerse considerablemente. Sin embargo, si tenemos una situación inestable, e.g. una depresión aislada de niveles altos (DANA) al oeste de Portugal, entonces las pasadas sucesivas pueden parecerse poco. La experiencia de los profesionales de la predicción tiene en cuenta estas pautas, que pueden orientar bastante sobre la confianza en las salidas del modelo.

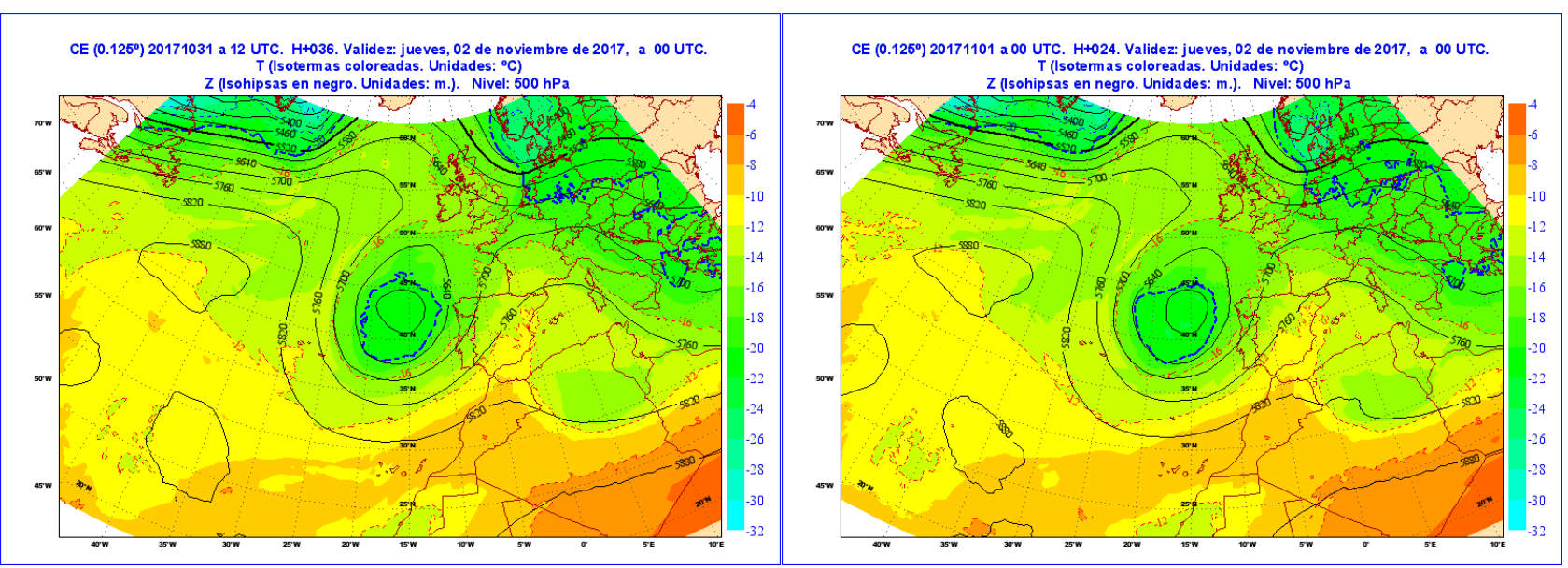

Figura 13.2: Dos pasadas consistentes del mismo modelo válidas para un mismo instante futuro: jueves 2 de noviembre de 2017 a las 00 UTC). Se muestran los campos de altura geopotencial y temperatura en 500 hPa. AEMET 2017. 


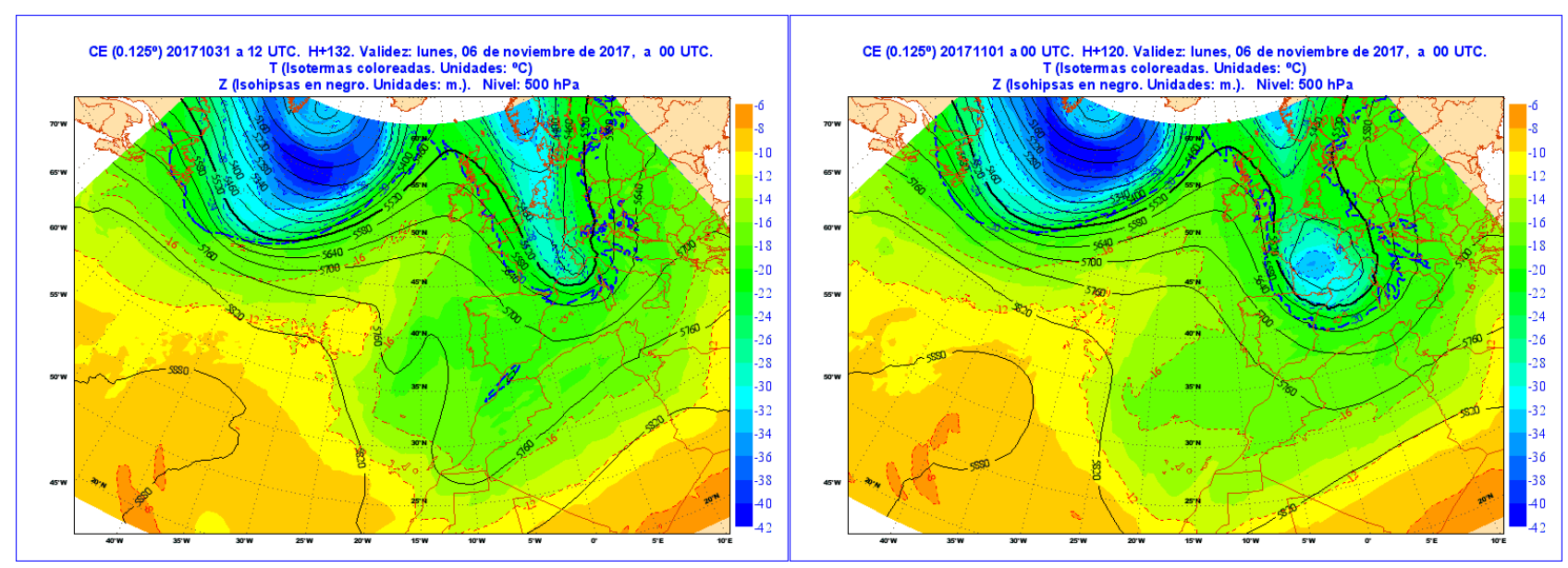

Figura 13.3: Dos pasadas, esta vez inconsistentes, del mismo modelo válidas para un mismo instante futuro: lunes 6 de noviembre de 2017 a las 00 UTC). Los campos son como en la Figura 13.2. AEMET 2017.

Como ejemplo, la Figura en la página anterior muestra las pasadas del 31 de octubre de 2017 a las 12 UTC alcance de $\mathrm{T}+36$ horas, es decir 2017103112+036 (izquierda) y 2017110100+024 (derecha), ambas válidas para el 2 de noviembre de 2017 a las 00 UTC, es decir, 2017110200. Se muestran los campos de altura geopotencial y temperatura en $500 \mathrm{hPa}$, ingredientes habituales en predicción operativa para diagnosticar la atmósfera en niveles medio-altos, identificando estructuras de importancia y significado dinámico. A escala sinóptica, vemos una dorsal de geopotencial con eje en el Mediterráneo occidental, con dorsal térmica asociada retrasada sobre el área mediterránea peninsular, seguida de una vaguada de geopotencial al oeste de la península ibérica, con núcleo frío, en fase, de $-20^{\circ} \mathrm{C}$. Las dos pasadas muestran escenarios consistentes, por tanto la confianza en el modelo es alta.

Por otro lado, la Figura 13.3 muestra las pasadas de $2017103112+132$ (izquierda) y $2017110100+120$ (derecha), ambas válidas para 2017110600 (lunes 6 de noviembre de 2017 a las 00 UTC). Se muestran los mismos campos que en la Figura 13.2 en la página anterior para ofrecer una interpretación similar. En esa escala sinóptica, vemos que la dorsal queda ya muy lejos al este (Europa Central), casi fuera del mapa y que la vaguada se ha desplazado hacia el este, pero ha evolucionado de formas distintas en las dos pasadas. A la izquierda vemos una vaguada, sobre Francia, de estructura más afilada, con más vorticidad sobre su eje y con un núcleo relativamente frío de $-28^{\circ} \mathrm{C}$, mientras que a la derecha vemos una vaguada más redondeada, con menos vorticidad en el eje, con un núcleo frío en fase, más estructurado y más frío que en la otra, de unos $-34^{\circ} \mathrm{C}$. En este caso, las dos pasadas muestran escenarios relativamente inconsistentes, por tanto la confianza en el modelo no es alta y el predictor tendrá que poner especial atención, sobre todo en el noroeste peninsular y Baleares, donde ese núcleo más o menos frío y más o menos presente podrá provocar actividad más o menos intensa.

\subsubsection{Consistencia entre modelos}

Una segunda comprobación se hace, en predicción operativa, comparando para una situación las salidas de dos o más modelos diferentes, válidas para el mismo área y momento futuro. Por ejemplo, en el anterior Instituto Nacional de Meteorología (INM) y, según las épocas, podían examinarse las salidas de los modelos inglés, francés, alemán, «centro europeo» (ECMWF), etc. Esta técnica, junto con el auténtico multimodelo (subsec. 13.5.2 en la página 174), ha venido a llamarse el SPC del hombre pobre, poor man EPS en inglés $[2,15,54]$. La consistencia entre modelos también está relacionada con la situación atmosférica: es dependiente del flujo. Ambas pruebas de consistencia, entre pasadas y entre modelos, pueden combinarse. El profesional de la predicción busca, sobre todo en las situaciones difíciles de predecir, estas pruebas de consistencia para medir el grado de confianza que puede otorgar a los modelos que maneja. En la parte izquierda de la Figura 13.4 en la página siguiente podemos ver predicciones de diferentes modelos globales para un mismo día de 1998, modelos usados, algunos sistemática y otros ocasionalmente, en los años 90 en AEMET. Ese uso debía acompañarse de medidas objetivas de calidad (cap. 15.2.3 en la página 211) de los citados modelos, que podemos ver en la parte derecha de la Figura 13.4 en la página siguiente. 

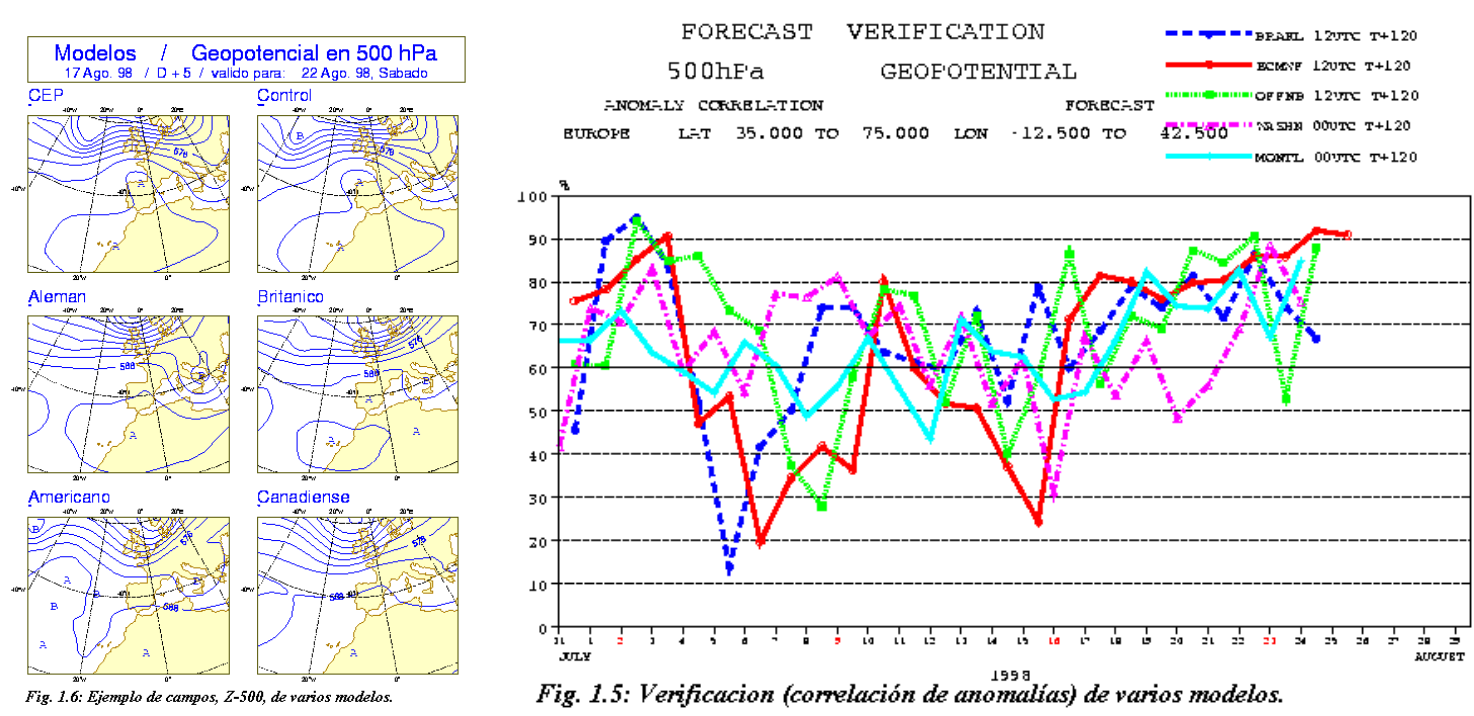

Fig. 1.5: Verificacion (comelación de anomalias) de varios modelos.

Figura 13.4: Antes de los SPC se utilizaban en ocasiones distintos modelos para estimar y delimitar su predecibilidad, izquierda, acompañando la información con medidas de calidad de los mismos, derecha (ver texto). AEMET 1998 y ECMWF 1998.

Cuando se trata de campos de tiempo presente, como la temperatura, el viento o la precipitación, las diferencias pueden ser más notables. En la Figura 13.5 podemos ver la precipitación acumulada en $24 \mathrm{~h}$, desde el miércoles a las 00 UTC hasta el jueves a las 00 UTC, prevista por dos modelos diferentes. A la izquierda, el modelo ECHRES (sec. 19.2 en la página 291), pasada de 2017103112+036. A la derecha, el modelo HARMONIE-AROME, misma pasada de 2017103112+036. Mientras que los dos modelos ven precipitación de escala sinóptica en el oeste de Galicia, HARMONIE, por su mayor resolución $(2.5 \mathrm{~km}$ sobre $9 \mathrm{~km}$ ) y su naturaleza (no hidrostático), es capaz de ver precipitación influenciada por factores de menor escala, como son la orografía o fenómenos convectivos, en zonas como Extremadura, entorno de la Comunidad Valenciana o franja mediterránea al este de Baleares. Para la labor del predictor poder contar con varios modelos aumenta su carga de trabajo pero le brinda más información para evaluar la confianza en los mismos. La inconsistencia entre dos modelos es un factor habitual que obliga a interpretar concienzudamente y aportar un gran valor añadido.

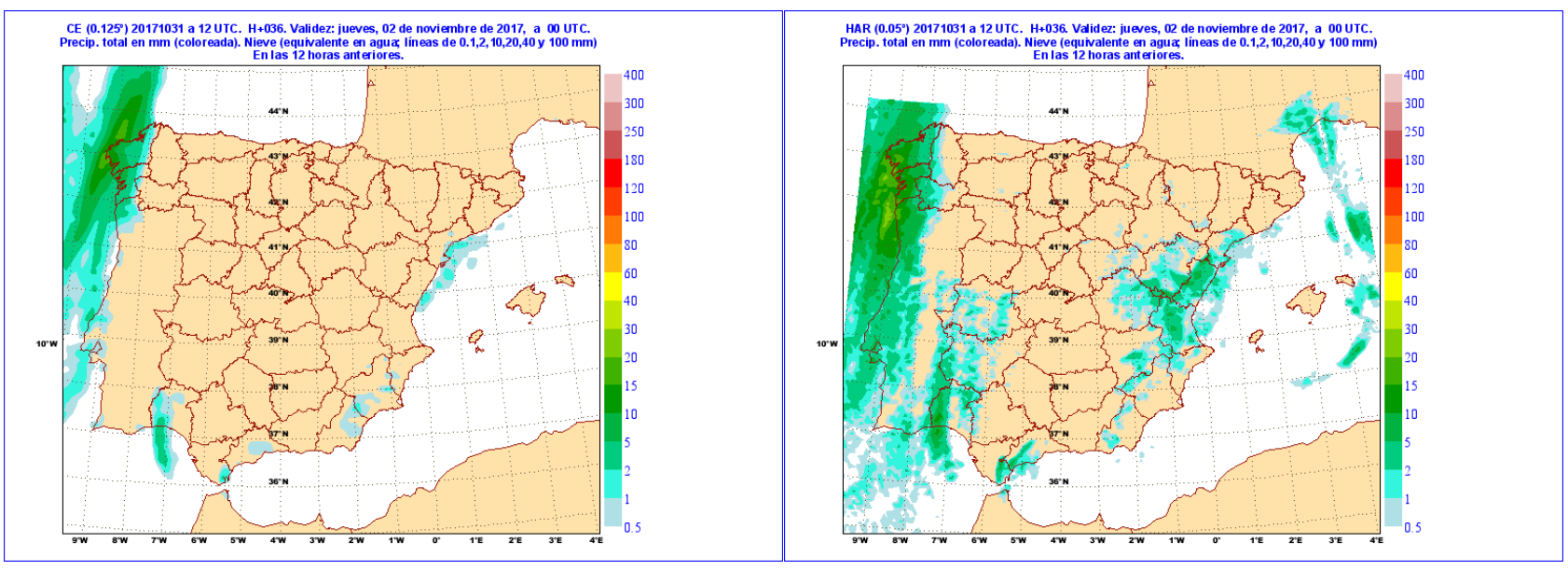

Figura 13.5: Campos de precipitación acumulada de dos modelos, inconsistentes, válidos para un mismo instante futuro: jueves 2 de noviembre de 2017 a las 00 UTC). A la izquierda ECHRES y, a la derecha, HARMONIE-AROME que muestra señal consistente en Galicia pero presenta patrones en otras regiones que no ve ECHRES. AEMET 2017. 


\subsection{Objetivos de un sistema de predicción probabilista}

Una vez que aceptamos que los modelos atmosféricos deterministas son siempre susceptibles de errores e incertidumbres, con graves implicaciones en la predicción de algunas situaciones y días del año, si queremos mejorar la predicción del tiempo hemos de volcar nuestras esperanzas en sistemas de predicción probabilistas. Una vez explorados los fundamentos de la problemática de la predecibilidad (cap. 12 en la página 155), podemos establecer los objetivos que esperamos de forma plausible de un sistema de predicción probabilista.

Estimar la función de densidad de probabilidad (PDF) de los estados de predicción. El estado atmosférico no va a ser un punto en el espacio de fases, sino que será un región, más o menos compacta, de ese espacio de fases: un conjunto de situaciones plausibles, meteorológicamente hablando, no necesariamente todas con la misma probabilidad, pero todas ellas posibles. Describimos esas probabilidades mediante una función de densidad de probabilidad (probability density function en inglés, con las siglas PDF).

Simular el efecto de las diversas fuentes de error o incertidumbre en la predicción. Existen dos fuentes principales de error o incertidumbre en la evolución prevista por el modelo atmosférico: en las condiciones iniciales y en la formulación del modelo (secs. 5.2 en la página 56 y 5.3 en la página 62). Al describir el estado atmosférico con una PDF, esperamos estimar el efecto de estas fuentes de incertidumbre.

Identificar áreas de predecibilidad potencialmente baja. En la evolución de la PDF atmosférica simula- da, habrá regiones del dominio donde se presente más dispersión y por tanto haya, a priori, más incertidumbre. Esas regiones con más dispersión e incertidumbre serán candidatas a regiones con poca predecibilidad.

Calibrar la predecibilidad dependiente del flujo. La predecibilidad atmosférica es mayor o menor según el tipo de situación, es decir, según el patrón o flujo atmosférico. Por eso se dice que la predecibilidad es dependiente del flujo. Mediante un sistema predictivo probabilista pueden establecerse relaciones entre los diversos patrones o situaciones atmosféricas y la predecibilidad correspondiente. Este sería un proceso de calibración de esa dependencia de la predecibilidad con el flujo.

Permitir al usuario estimar la probabilidad de diferentes escenarios de tiempo. El estado atmosférico, descrito por una PDF, tendrá diferentes posibilidades o escenarios. Con la PDF podemos estimar la probabilidad de los diferentes escenarios, para ello hay muchas técnicas posibles (sec. 13.5 en la página 174).

Evaluar el potencial de fenómenos adversos. Algunos de los escenarios previstos por el sistema de predicción probabilista implicarán fenómenos meteorológicos adversos (FMA) de uno u otro tipo. Conociendo la probabilidad de cada escenario, podemos evaluar las probabilidades de diferentes FMA. Estos FMA, por su naturaleza, aparecen normalmente en la cola de la distribución de la PDF.

Ahora bien, llegó el momento de responder a la pregunta crucial. ¿Cómo generar una PDF que represente el estado atmosférico, en el contexto de los modelos numéricos? (Figura 13.6).

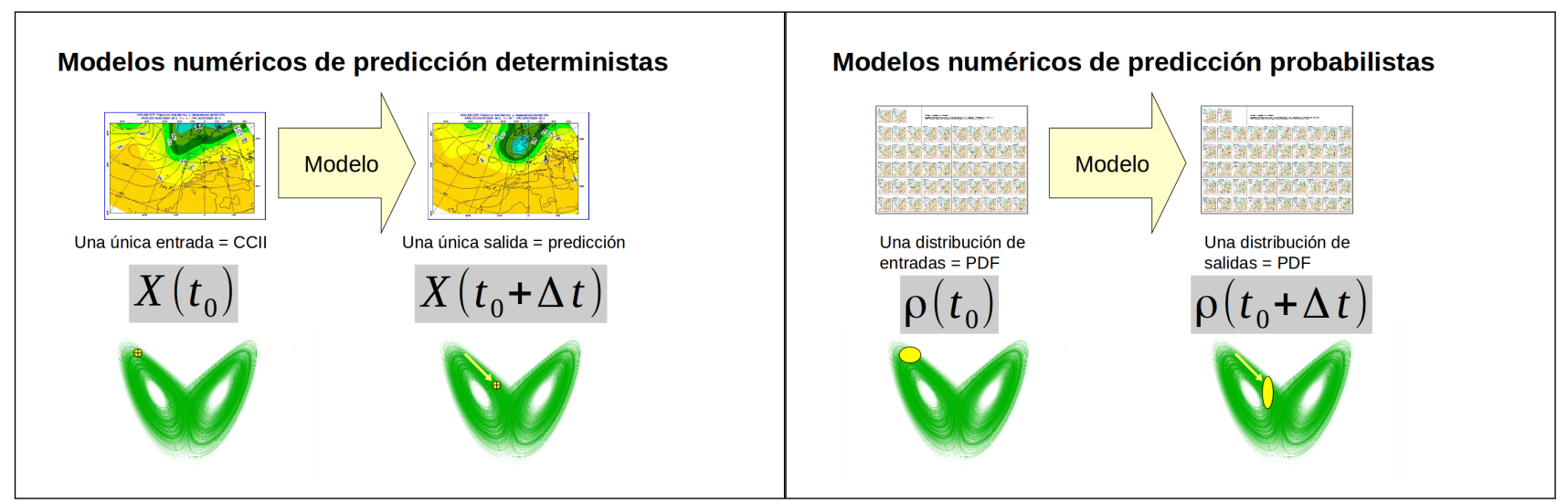

Figura 13.6: ¿Cómo generar una PDF que represente el estado atmosférico, en el contexto de los modelos numéricos? Es decir, ¿cómo pasar de la esquema determinista (izquierda) al esquema probabilista (derecha)? (ver texto). 


\subsection{Sistemas de predicción por conjuntos (SPC)}

Todavía no existe (2018) un formalismo teórico con el que representar las diversas fuentes de incertidumbre en los modelos atmosféricos durante el periodo de predicción. El abordaje teórico del problema de la predecibilidad consistiría por tanto, de forma muy directa, en resolver la ecuación que describe la evolución en el tiempo de la PDF atmosférica, la llamada ecuación de FOKKER-PLANK.

Ecuación de FoKKer-Planck, también llamada ecuación de Kolmogorov. Esta ecuación describe la evolución en el tiempo de la función densidad de probabilidad, PDF, de la velocidad de una partícula bajo la influencia de fuerzas de resistencia y fuerzas aleatorias, como el movimiento Browniano. En el caso de distribuciones de posición, se denomina ecuación de SMOLUCHOWSKI y, entonces, es equivalente a la ecuación de convección-difusión. En ausencia de difusión se conoce como ecuación de LIOUVILLE (ver teorema de LIOUVILLE en la sección 5.1.4 en la página 54). En el caso unidimensional más sencillo, la ecuación de FOKKER-PLANCK tiene este aspecto:

$$
\frac{\partial}{\partial t} p(x, t)=-\frac{\partial}{\partial x}[\mu(x, t) p(x, t)]+\frac{\partial^{2}}{\partial x^{2}}[D(x, t) p(x, t)]
$$

donde $\mu(x, t)$ es la deriva, $D(x, t)$ el coeficiente de difusión y $p(x, t)$ la función densidad de probabilidad, PDF, de la variable aleatoria $x$.
Esta ecuación solo tiene solución analítica bajo circunstancias especiales. Un modelo atmosférico típico contiene unas $10^{8}-10^{9}$ variables aleatorias o grados de libertad, lo que hace computacionalmente inabordable integrar la ecuación de FOKKER-PLANCK o incluso la de LIOUVILLE.

Dado que actualmente (2018) resulta inabordable resolver esta ecuación, los métodos investigados con éxito a finales del siglo XX se basan en explorar el espacio de estados atmosféricos plausibles descrito en la sección 5.1.4 en la página 53. Esta exploración puede ser total, tipo método de Montecarlo, o selectiva, seleccionando algunos aspectos más importantes a la hora de muestrear.

El primer paso sería medir el estado inicial de la atmósfera, pero ya sabemos que no puede conocerse con exactitud: los datos del análisis (sec. 10.3 en la página 133) contienen siempre un error que sólo podemos estimar. Esta inexactitud en la medida del estado atmosférico conduce a admitir la existencia de un gran número de estados o condiciones iniciales compatibles con las medidas realizadas. Usando un solo modelo, que predecirá un único estado futuro de la atmósfera, podremos generar múltiples predicciones, cada una de ellas determinista, tomando como punto de partida condiciones iniciales ligeramente diferentes pero igualmente probables, caracterizando así, con estas múltiples predicciones, la incertidumbre en la predicción[41].
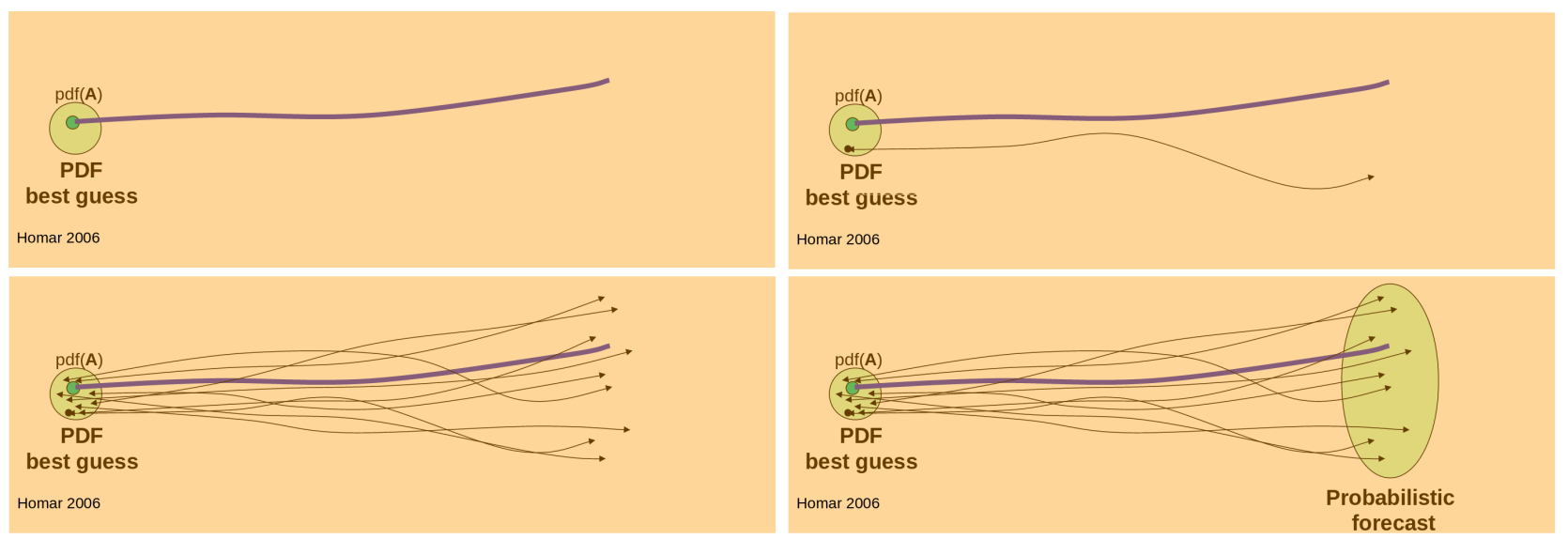

Figura 13.7: Exploración del espacio de estados atmosféricos plausibles: se toma una muestra de estados iniciales, construyendo así una buena aproximación (best guess en inglés) de la PDF del estado inicial. Esos estados iniciales se hacen evolucionar independientemente, en la ilustración primero uno, luego otro y luego el resto de modo que, finalmente, podemos delinear una estimación de la PDF de estados atmosféricos previstos, lo que viene a llamarse sistema de predicción probabilista (ver texto) (imágenes de VícTOR HOMAR). 
Así pues, la exploración empieza por tomar, o construir, muestras de estados iniciales y haciendo evolucionar cada uno independientemente, para obtener una serie de estados previstos. De este modo construimos una estimación de la PDF inicial, así como una estimación de la PDF discretizada en los diversos momentos de la evolución del sistema. En la Figura 13.7 en la página anterior se ilustra esta idea. En estrecha relación con los métodos de asimilación (sec. 16.1 en la página 244), sí que existen formalismos para estimar la estadística del error en las condiciones iniciales, e. g. función de coste $\mathrm{J}$ en análisis variacional (ec. 16.6 en la página 247) y, aunque todavía está en desarrollo el terreno común de la asimilación de datos por conjuntos, EDA (sec. 16.2.5 en la página 248), los resultados alumbran un camino claro a seguir.
Esta generación de predicciones igualmente probables introduce la concepción de predicción probabilista. Una aproximación práctica a la misma usando modelos atmosféricos es la denominada sistemas de predicción por conjuntos, SPC.

Además de muestrear las incertidumbres en condiciones iniciales, es necesario introducir también el muestreo de las incertidumbres y errores debidos al modelo (cap. 17 en la página 257). En la práctica y, describiéndolo de un modo menos teórico, las técnicas de generación de SPC pueden dividirse así en dos grandes grupos, según que se hagan perturbaciones en las condiciones iniciales o perturbaciones en el modelo, para muestrear las incertidumbres correspondientes.

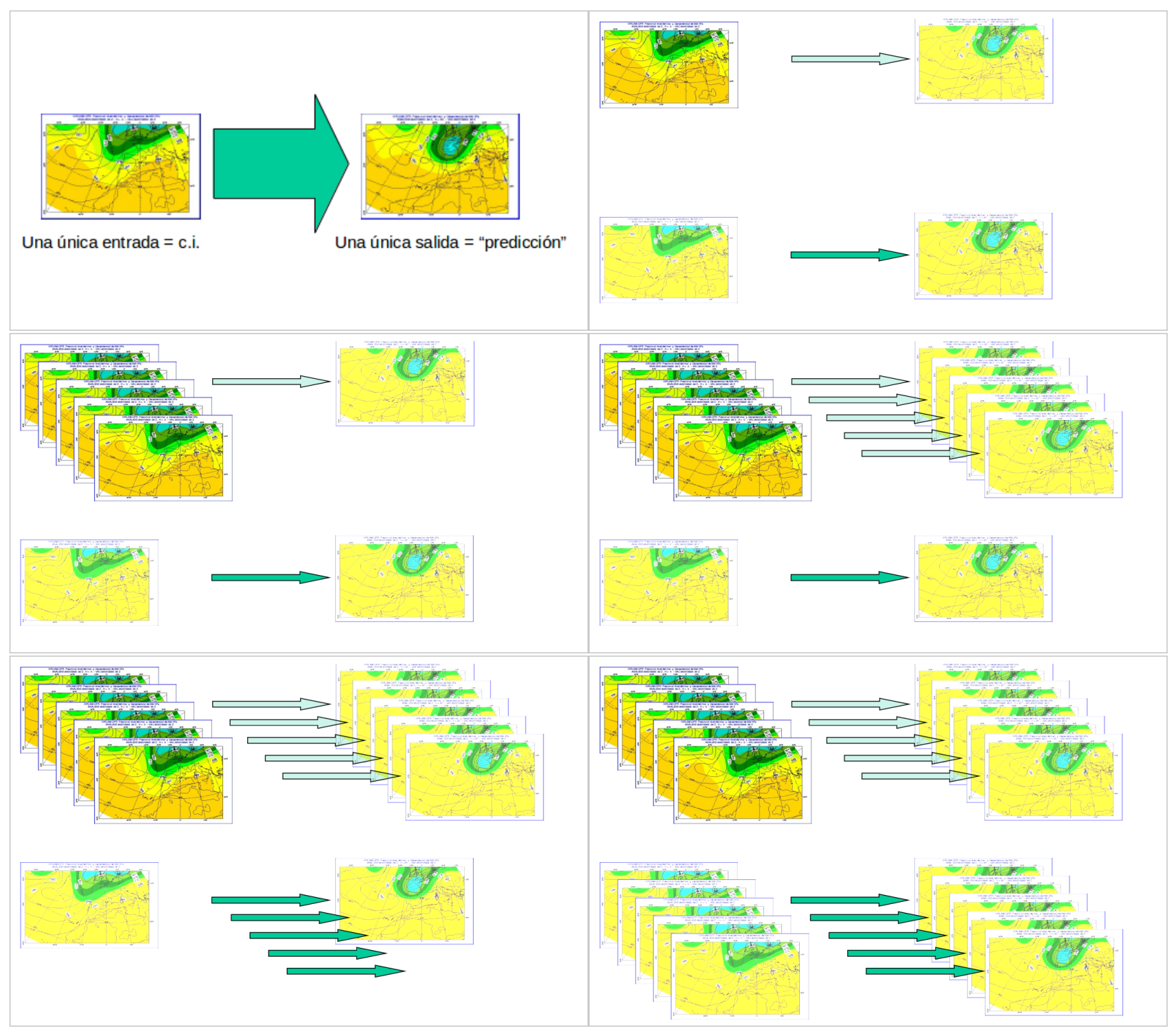

Figura 13.8: Dado el esquema conceptual de cómo funciona un modelo numérico, fila de arriba, aparecen los dos grandes grupos de métodos de generación de SPC en la práctica: perturbaciones en las condiciones iniciales, fila del centro y, finalmente, perturbaciones en el modelo, fila de abajo (ver texto). 
En la Figura 13.8 en la página anterior se ilustran estos dos grandes grupos. En la imagen superior izquierda tenemos el esquema, ya presentado en varias ocasiones, de cómo funciona un modelo numérico determinista de predicción: una condición inicial (mapa izquierdo), un modelo (flecha verde simbolizando el proceso de predicción) y una predicción (mapa derecho). En la imagen superior derecha preparamos dos métodos de perturbaciones: en CCII arriba y en modelo abajo. En la fila central se ilustra la perturbación en las CCII: se genera una muestra de diversas CCII similares, pero no idénticas (izquierda) y, para cada una de ellas, se usa el modelo para hacer la predicción y saber el estado final, de modo que tendremos una serie de predicciones distintas (derecha). En la fila inferior se ilustra la perturbación en el modelo: a partir de una única condición inicial se usan diversas versiones del modelo (izquierda) para obtener diversas predicciones (derecha).

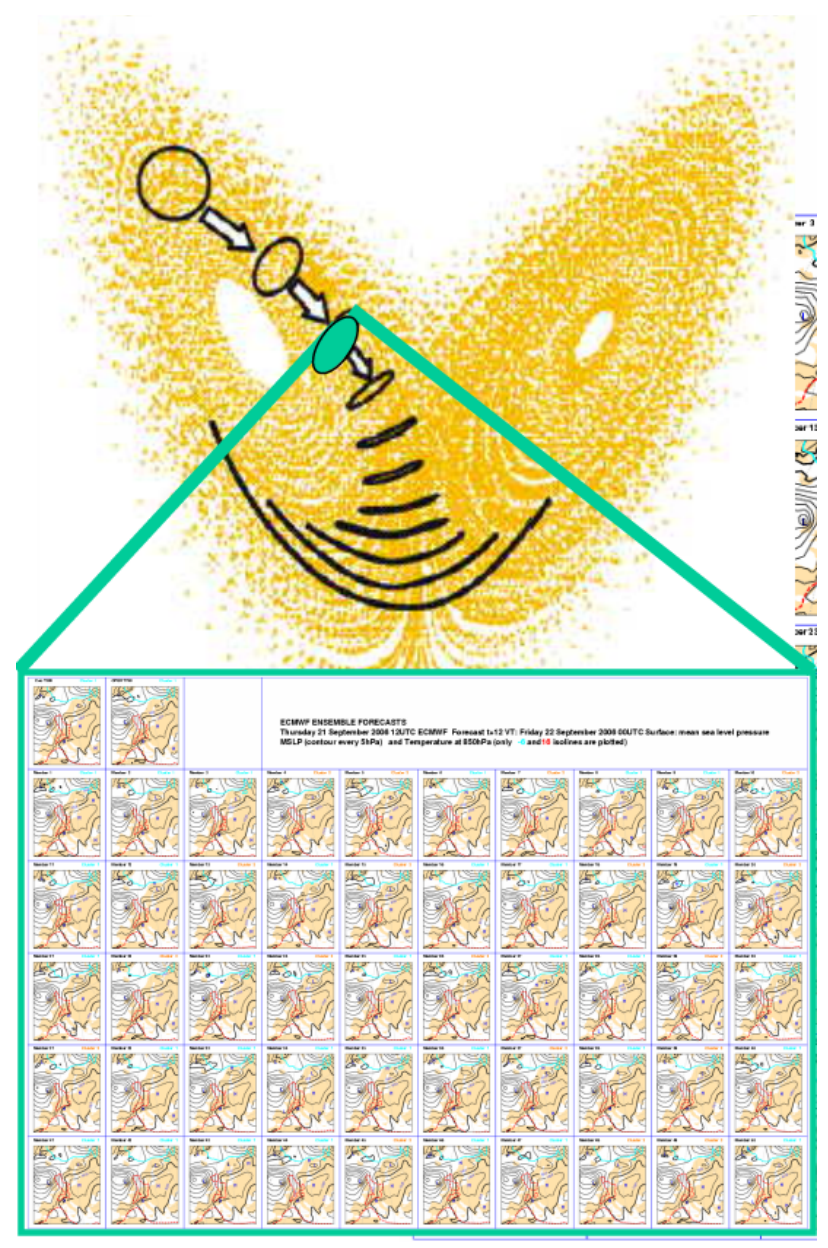

Figura 13.9: ¿Qué es un sistema de predicción por conjuntos? Es un sistema que intenta estimar la evolución de la PDF atmosférica (elipse turquesa en el dibujo) mediante un conjunto de escenarios atmosféricos plausibles, tanto iniciales como previstos (sellos en el dibujo) en el periodo de predicción.

\subsection{1 ¿Qué es un SPC? Miembros y esce- narios}

Con los conceptos introducidos en secciones y capítulos previos, estamos en disposición de definir un Sistema de Predicción por Conjuntos, SPC (Ensemble Prediction System, EPS en inglés): es una aproximación probabilista a la predicción numérica del tiempo, en forma de sistema que intenta estimar la evolución de la PDF atmosférica mediante un conjunto de escenarios atmosféricos plausibles, tanto iniciales como previstos en los sucesivos instantes del periodo de predicción. Esta concepción se ilustra en la Figura 13.9.

Con diferentes métodos, se computa un conjunto de condiciones iniciales plausibles y un conjunto de predicciones válidas o escenarios para un determinado rango temporal y para la misma zona geográfica. A esas predicciones o escenarios los denominamos miembros del SPC. Esperamos de este conjunto que satisfaga una serie de propiedades:

- Es una estimación, discreta, de la PDF del estado atmosférico esperado.

- Nos permite pensar en diferentes escenarios, consistentes con las condiciones iniciales y el modelo.

- Nos da información cuantitativa, detallada y explícita de la incertidumbre en la predicción y, por ende, de la predecibilidad, así como del potencial de fenómenos adversos, que aparecerán normalmente en la cola de la distribución de la PDF.

- Tradicionalmente y debido al coste computacional, los miembros de los SPC son usualmente de menor resolución que los modelos deterministas. Sin embargo, en la estrategia del ECMWF (sec. 19.4 en la página 297) para el periodo 20162025 está el centrar sus esfuerzos principales en su ECENS (sec. 19.3 en la página 293), de modo que el ECHRES ya no abarcará la mitad de los recursos computacionales. En ese sentido, estamos en el umbral de una nueva era en la que las predicciones se realizarán usando principalmente SPC.

Los SPC se producen operativamente en muchos centros de predicción del tiempo y el clima repartidos por todo el mundo (cap. 26 en la página 387). Destacan como pioneros en este aspecto el European Centre for Medium-range Weather Forecasts -Centro Europeo de Predicción a Plazo Medio- (ECMWF) [46], los Centros Americanos de Predicciones Ambientales, National Centres for Environmental Predictions, NCEP [65] y el Servicio Meteorológico Canadiense, Meteorological Service of Canada, MSC [52]. 


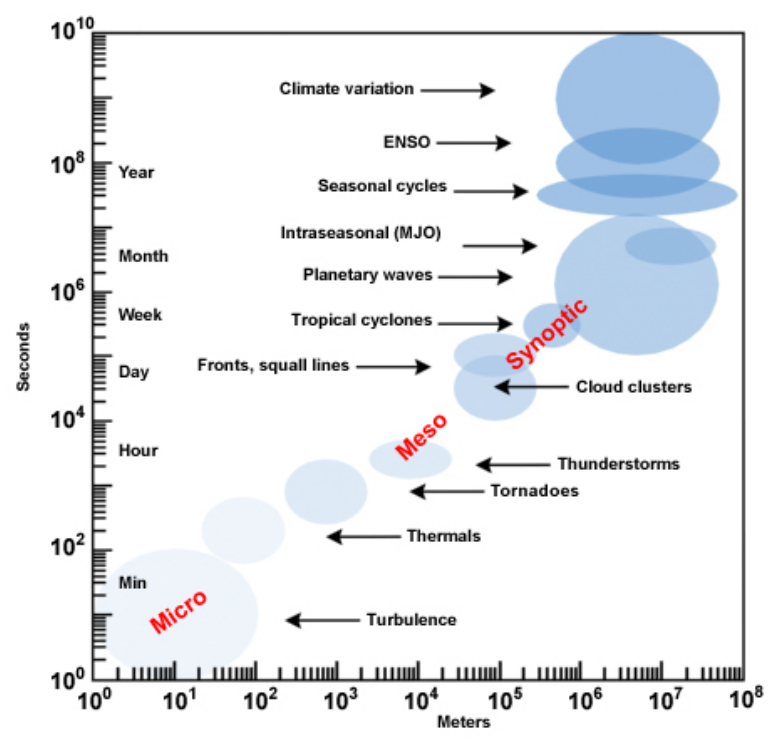

Figura 13.10: Relación entre escalas espaciales y temporales para los distintos fenómenos meteorológicos. COMET.

\subsection{Diseño de SPC}

\subsubsection{Escalas y plazos}

$\mathrm{Al}$ igual que sucede con los modelos atmosféricos deterministas, los SPC heredan de la dinámica atmosférica subyacente la relación íntima entre las escalas de tiempo espacial y temporal que ilustra la Figura 13.10: fenómenos de más tamaño se desarrollan y tienen su ciclo de vida en tiempos más largos (sec. 6.3 en la página 77) [49]. De este modo, los SPC globales cubriendo el planeta entero describen de forma natural los fenómenos de escala planetaria y sinóptica y se utilizan idealmente para predicciones de medio y largo plazo (sec. 4.2.3 en la página 33), estacionales, anuales y, más allá, para proyecciones del clima y del cambio climático. Los SPC regionales están asociados naturalmente a fenómenos sinópticos o de mesoescala alpha (cap. 21 en la página 313), siendo ideales para predicción en el corto plazo (sec. 4.2.2 en la página 32). Los SPC, por último, de mesoescala y escala kilométrica o convectiva son óptimos para la predicción a muy corto plazo y la vigilancia o nowcasting dado que resuelven explícitamente la convección (sec. 4.2.1 en la página 31).

\subsubsection{SPC globales}

En la práctica hay muchos métodos dentro de cada grupo de los dos mencionados anteriormente, perturbaciones en la condiciones iniciales o en el modelo.
En conjunto, esta metodología formaría una disciplina que podríamos llamar diseño de SPC a la que se dedica una parte de este libro, un capítulo de perturbaciones en condiciones iniciales, otro sobre las que se hacen en el modelo y un tercer capítulo con aquellas realizadas en las condiciones de contorno. Aquí damos un breve resumen de técnicas, sin entrar en excesivo detalle, para tener una perspectiva general.

Montecarlo. Se generan muchos estados iniciales de manera aleatoria, sin seleccionar aquellos que puedan resultar más críticos [30, 64]. Fue uno de los primeros métodos propuestos para generar SPC de estados iniciales [31, 41, 48].

Time-lag o desfase temporal. Se usan predicciones de diferentes pasadas, es decir predicciones hechas con varios análisis consecutivos en el tiempo, técnica llamada a menudo lagged average forecast, LAF [30, 42, 53]. Dado que cuanto más reciente es el análisis más calidad suele tener la predicción, opcionalmente puede usarse una ponderación, en cuyo caso se llama scaled LAF, SLAF [16].

Multimodelo. Se combinan salidas de varios modelos, con o sin pesos. Esta técnica se probó con excelentes resultados en el Experimento de Ensembles de Mesoescala y Tormenta, Storm and Mesoscale Ensemble Experiment, SAMEX [12, 19, 20, 23, 32, 40, 51]. Se comparó la técnica multimodelo a base de modelos TIGGE (sec. 26.1 en la página 388) con el ECENS (sec. 19.3 en la página 293) calibrado y sin calibrar, resultando muy difícil obtener mejor rendimiento que las combinaciones multimodelo [23]. 
Multianálisis. Se combinan distintas integraciones del mismo modelo inicializado con diferentes análisis. Usando diferentes técnicas de asimilación caracterizamos las incertidumbres asociadas a las condiciones iniciales [20, 51]. Tomando diferentes modelos globales como distintas condiciones iniciales se consigue mejor rendimiento que con un solo modelo $[17,39$, 40, 72].

Métodos perturbativos en el análisis. Se generan perturbaciones en los subespacios donde el error en las condiciones iniciales crece más rápidamente, dependiendo del flujo atmosférico, identificando así selectivamente los componentes activos que dominarán el crecimiento del error. Se trata de muestreo selectivo, en oposición a Montecarlo que no lo es. Ejemplos de estos métodos son los vectores singulares (ECMWF $[10,26,27,46])$, los vectores criados (NCEP [38, 65, $66,67])$, las diferentes variedades de filtros de $\mathrm{KAL}$ MAN, e.g. LETKF [34, 57] o la puntera asimilación de datos por conjuntos, EDA [4, 6, 33, 34].

Multiparametrizaciones o multifísica. Se utilizan diferentes parametrizaciones de la física con el mismo modelo para muestrear las incertidumbres del modelo $[1,33,62,68,69]$.

Perturbaciones estocásticas. También se trata de muestreo selectivo y con perturbaciones, pero para el error del modelo. Se perturban las parametrizaciones para muestrear los errores del modelo en escala submalla [3, 9, 50, 58, 59].

A los métodos anteriores pueden añadirse métodos de posproceso estadístico $[19,21,55,60]$ a los que se dedica el capítulo 14 en la página 193. Todos los métodos mencionados, con el apropiado esfuerzo de compatibilización, pueden combinarse para producir SPC y, de hecho, actualmente es bastante común usar varias técnicas. E. g. En ECMWF se combinan las técnicas vectores singulares, EDA y parametrizaciones estocásticas [50]. La combinación de multimodelo, multianálisis con modelos globales y posproceso estadístico avanzado se ha venido probando con éxito y operacionalmente en el servicio meteorológico americano, National Centres for Environmental Prediction, NCEP [14, 24, 25, 63, 70], también en las costas noroeste [22] y noreste [37] de EE. UU., en el SPC de corto plazo de la Universidad de Washington [22].

\subsubsection{SPC regionales}

Los modelos regionales, en inglés Regional Circulation Model (RCM) o de área limitada, Limited Area Model (LAM), pueden usarse para generar SPC regionales, normalmente para su uso en el corto plazo, mientras que los globales quedarían para el uso en el medio y largo plazo.

Las fuentes de error en los SPC regionales son las mismas que en los globales, añadiendo ahora el efecto de las condiciones de contorno laterales, lateral boundary conditions, LBC. Éstas, junto con las condiciones iniciales, aportan una buena parte de la dispersión y la calidad que un SPC regional necesita (sec. 21.4 en la página 322). Una primera manera de generar SPC regionales por perturbación de condiciones de contorno es lo que llamaremos multicontorno.

Multicontorno: utilizar varios modelos globales como condiciones de contorno para nuestro SPC regional.

Downscaling. Otra manera usual de generar un SPC regional es hacer reducción de escala, downscaling (cap. 10 en la página 129), de un SPC global [35]. Opcionalmente, puede seleccionarse un subconjunto de miembros del SPC global mediante alguna técnica de agrupamiento [43, 44, 47]. En cualquier caso, los miembros del SPC global se utilizarán como condiciones iniciales y de contorno para el SPC regional.

Normalmente, las perturbaciones del SPC global desarrollan un rendimiento óptimo en el medio plazo a escala sinóptica, por lo que suele ser necesaria alguna técnica adicional. Se puede hacer multianálisis o multicontorno, i. e. correr el mismo modelo inicializado con diferentes análisis o conducido por diferentes condiciones de contorno. Al igual que con los SPC globales, pueden combinarse diferentes técnicas para producir SPC regionales. E. g. en AEMET se han estado generando SPC para el corto plazo combinando las técnicas multimodelo, multianálisis y multicontorno, uno llamado AEMET-SREPS [20] (cap. 21 en la página 313) y otro llamado AEMET- $\gamma$ SREPS (cap. 22 en la página 333 ). 

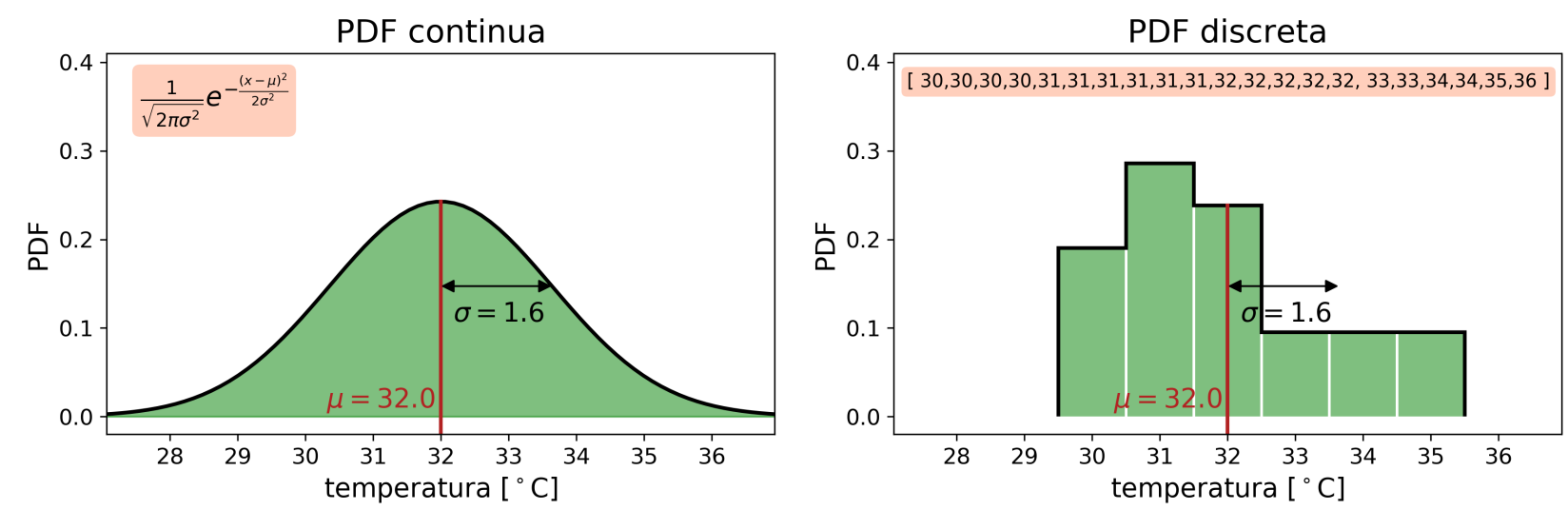

Figura 13.11: Izquierda: distribución de probabilidad. Derecha: distribución de frecuencia. Los detalles se abordarán a lo largo de la sección.

\subsection{Representación de la incerti- dumbre}

En el contexto de los SPC tratamos con variables denominadas aleatorias. En cada punto de malla del dominio del SPC, en cada instante en el tiempo y para cada parámetro meteorológico (temperatura, viento, precipitación...) tenemos una variable que podemos considerar aleatoria (toma valores, en principio, aleatorios, ver sección G.1.3 en la página 1020), donde los valores que nos brinda el SPC son una muestra de la población de valores plausibles. Esa muestra es una distribución, discreta o continua, de valores y contiene mucha información sobre la incertidumbre en la predicción del estado atmosférico, incertidumbre que puede representarse de forma cuantitativa, detallada y explícita. Describiremos aquí una serie de conceptos asociados y de técnicas importantes para representar la incertidumbre en la distribución:

- Distribuciones de probabilidad y de frecuencia.

- Medidas de de centralización: media, mediana, moda.

- Medidas de dispersión: desviación típica y rango intercuartílico

- Medidas de posición: máximo y mínimo, mediana y percentiles.

- Densidad de probabilidad (PDF) y probabilidad acumulada (CDF).

Por otro lado, algunas ideas y técnicas se mencionarán por completitud, pero para profundizar en ellas nos referiremos a otros capítulos:

- Técnicas de agrupamiento: están relacionadas con la dispersión y con la simplificación fiable de la información.
- Valores extremos y carácter extremo de una distribución: tienen que ver con la identificación y el tratamiento de situaciones que se hallan en la cola de las distribuciones climatológicas.

\subsubsection{Distribuciones de probabilidad y de frecuencia}

Consideremos una variable aleatoria $x$ cuya naturaleza desconocemos, al menos a priori. Su distribución de probabilidad es una función, normalmente teórica, que a cada suceso o valor de $x$ (o intervalo de valores) le asigna una probabilidad asociada. Esta distribución de probabilidad contiene información completa sobre el comportamiento de la variable aleatoria $x$, pero a priori no tenemos por qué conocer esta distribución. Puede inferirse información sobre la variable aleatoria tomando $N$ valores diferentes de $x$ que pertenezcan a la misma población y que llamaremos muestra. En la práctica, suele disponerse de ese conjunto limitado de datos llamado muestra, con el que mediante unas tablas apropiadas construimos una distribución de frecuencia: se dividen los datos o valores de $x$ en intervalos, asignando a cada intervalo la frecuencia correspondiente. Puede trabajarse con frecuencias absolutas o relativas. Por diferentes motivos, a menudo se realiza un ajuste de la distribución de frecuencia para obtener una distribución de probabilidad asociada. La distribución de frecuencia es, habitualmente, de naturaleza discreta: se trata de un conjunto finito de valores y su representación es un histograma de frecuencias (ver, por ejemplo, Figura 13.11 derecha). Por otro lado, la distribución de probabilidad puede ser continua: se trata de una función que cubre un abanico continuo de valores y su representación gráfica es, consiguientemente, en forma de función continua (ver, por ejemplo, Figura 13.6.1 izquierda). 


\subsubsection{Un ejemplo de predicción probabilis- ta SPC para un lugar y un momento}

Como decíamos, en el caso particular de los SPC, para cada punto geográfico, cada instante en el tiempo y cada variable meteorológica el SPC proporciona un conjunto de valores previstos, que llamamos miembros. Ese conjunto lleva asociada una distribución de frecuencia. Suponemos que la variable meteorológica es aleatoria en cierto sentido. Sus valores plausibles son una población, con una distribución de probabilidad que no conocemos exactamente. El SPC nos brinda una muestra de esa población: un conjunto limitado, discreto, de valores de esa variable aleatoria meteorológica. En eso precisamente consiste una predicción probabilista para un lugar y un momento.

Una predicción probabilista para un lugar y un momento. Por ejemplo, en el caso de temperatura prevista en Sevilla para el 8 de agosto de 2017 a las 18 UTC, los valores previstos por un SPC podrían ser: $30,30,30,30,31,31,31,31,31,31,32,32$, 32, 32, $32,33,33,34,34,35,36$. Construimos la tabla de frecuencias correspondiente, ilustrada en la Tabla 13.1. La media (sec. 13.6.3 en la página siguiente) de los valores es, aproximadamente, $32.0^{\circ} \mathrm{C}$ y la desviación típica (sec. 13.6.5 en la página 181) $1.6^{\circ} \mathrm{C}$.

\begin{tabular}{|c|c|c|}
\hline $\begin{array}{c}\mathrm{T} \\
{\left[{ }^{\circ} \mathrm{C}\right]}\end{array}$ & $\begin{array}{c}\text { frecuencia } \\
\text { absoluta }\end{array}$ & $\begin{array}{c}\text { frecuencia relativa } \\
\text { (redondeada) }\end{array}$ \\
\hline \hline 30 & 4 & 0.19 \\
\hline 31 & 6 & 0.29 \\
\hline 32 & 5 & 0.24 \\
\hline 33 & 2 & 0.10 \\
\hline 34 & 2 & 0.10 \\
\hline 35 & 1 & 0.05 \\
\hline 36 & 1 & 0.05 \\
\hline total & 21 & 1 \\
\hline
\end{tabular}

Tabla 13.1: Distribución de frecuencias asociada a los valores hipotéticos previstos por un SPC de temperatura en Sevilla para el 8 de agosto de 2017 a las 18 UTC: $30,30,30,30,31,31,31,31,31,31,32,32,32,32$, 32, 33, 33, 34, 34, 35, 36. La frecuencia absoluta es el numero de ocurrencias del valor. La frecuencia relativa es la frecuencia absoluta dividida entre el número total de valores y ha de sumar uno. Esta distribución puede representarse gráficamente en un histograma de frecuencias como el de la Figura 13.21 en la página 187 derecha.

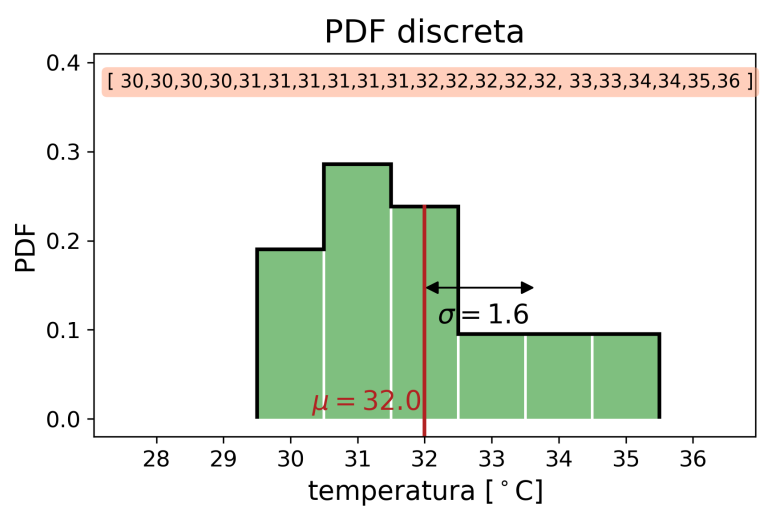

Figura 13.12: Distribución de frecuencia correspondiente a los valores de la Tabla 13.1.

Por simplicidad, hemos construido un ejemplo con 21 miembros solamente y, además, cuyos valores de temperatura son números enteros. En casos más realistas el número de miembros puede ser mayor y sus valores son números reales representados con decimales. En esos casos, los intervalos son los mismos que los usados en la Tabla 13.1, y la frecuencia de cada clase o intervalo de clase es el número de valores que caen dentro. La marca central de cada clase o intervalo es un número entero, y sus límites son ese número más menos media unidad.

Intervalos de clase en el ejemplo. En el ejemplo que hemos construido, las clases o intervalos de clase, con 1 marca de cada una de las clases, se reflejan en la siguiente tabla:

\begin{tabular}{|c|c|}
\hline intervalo & marca \\
\hline \hline$[29.5,30.5)$ & 30 \\
\hline$[30.5,31.5)$ & 31 \\
\hline$[31.5,32.5)$ & 32 \\
\hline$[32.5,33.5)$ & 33 \\
\hline$[33.5,34.5)$ & 34 \\
\hline$[34.5,35.5)$ & 35 \\
\hline$[35.5,36.5)$ & 36 \\
\hline
\end{tabular}

Nótese que los intervalos respectivos son semiabiertos: cerrados por la izquierda, abiertos por la derecha, para que no haya solapamientos. Con esta partición en intervalos pueden tratarse valores continuos de la variable aleatoria. Por ejemplo, un valor de 30.9 caería dentro del intervalo $[30.5,31.5)$ y se asignaría a la marca central de dicho intervalo, es decir, al valor $31{ }^{\circ} \mathrm{C}$. 


\subsubsection{Medidas de centralización: media, mediana, moda}

El promedio estadístico de una distribución es una primera medida de centralización. Aunque es sencillo de calcular, puede desorientar y por ello se debe considerar el uso de la mediana o la moda, o bien acompañar con medidas de dispersión y/o posición.

Promedio o media. Para una PDF continua teórica la media $\bar{x}$ viene dada por:

$$
\bar{x}=\int_{-\infty}^{+\infty} x f(x) d x
$$

Para una distribución de valores discretos:

$$
\bar{x}=\frac{1}{N} \sum_{i=1}^{N} x_{i}
$$

Mediana y moda. En una distribución de datos ordenada, la mediana es el dato central, aquel que separa la distribución en dos partes iguales. Tiene propiedades estadísticas que la hacen más conveniente que la media: es más robusta, es decir, no es sensible a la presencia de valores atípicos (outliers) y es más resistente, es decir, no depende críticamente de la distribución de probabilidad subyacente. A pesar de ser la mediana más robusta y resistente, se utiliza la media usualmente en centros operativos de SPC, por razones inerciales. Cuando, en una distribución de frecuencia, se agrupan los datos en intervalos, la moda es el intervalo con la frecuencia más alta.

\begin{abstract}
Medidas de centralización para el ejemplo. Recordemos el caso de temperatura prevista en Sevilla para el 8 de agosto de 2017 a las 18 UTC, con valores previstos: $30,30,30,30,31,31,31,31$, 31, 31, 32, 32, $32,32,32,33,33,34,34,35,36$ (medidas en ${ }^{\circ} \mathrm{C}$ ). La media o promedio de los valores es, aproximadamente, 32. La mediana es 32, pues divide a la distribución en dos partes iguales. La moda es 31 pues el valor con mayor frecuencia (ver tabla 13.1 en la página anterior). En este caso media y mediana coinciden, pero no siempre lo hacen: cuanto más asimétrica la distribución, menos se parecen.
\end{abstract}

\subsubsection{Crítica al uso del promedio de un SPC}

Dado un SPC, en cada punto de malla y cada instante de tiempo previsto, tenemos una distribución de predicciones para cada variable, e. g. la temperatura y por tanto podemos calcular el promedio de las predicciones de temperatura del SPC en ese punto de malla e instante del futuro. Pero el promedio aritmético de los valores de los miembros de un SPC no es siempre una situación meteorológica físicamente plausible y consistente. Este hecho se debe a que el promedio aritmético es resultado de una operación estadística y no proviene de un modelo atmosférico en el que se garantice que se cumplen las diversas ecuaciones de conservación, continuidad, etc. [7, 8, 11, 20].

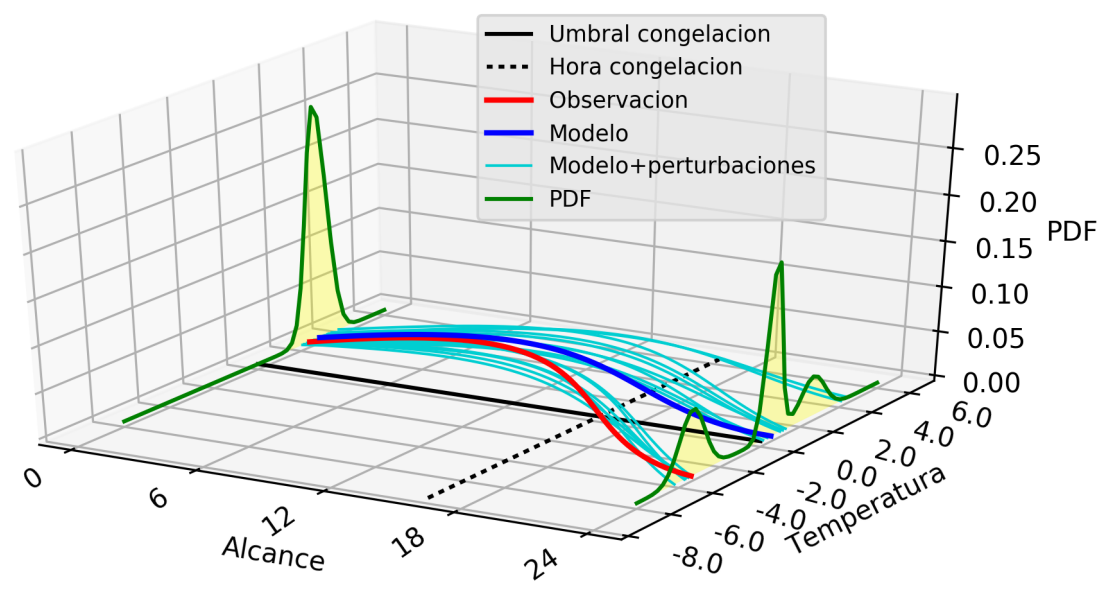

Figura 13.13: Problema de la predecibilidad desde el punto de vista cotidiano de un predictor del tiempo con una PDF inicial en el plano izquierdo, unas curvas de evolución en el plano inferior y una PDF prevista en el plano derecho. (ver texto). 


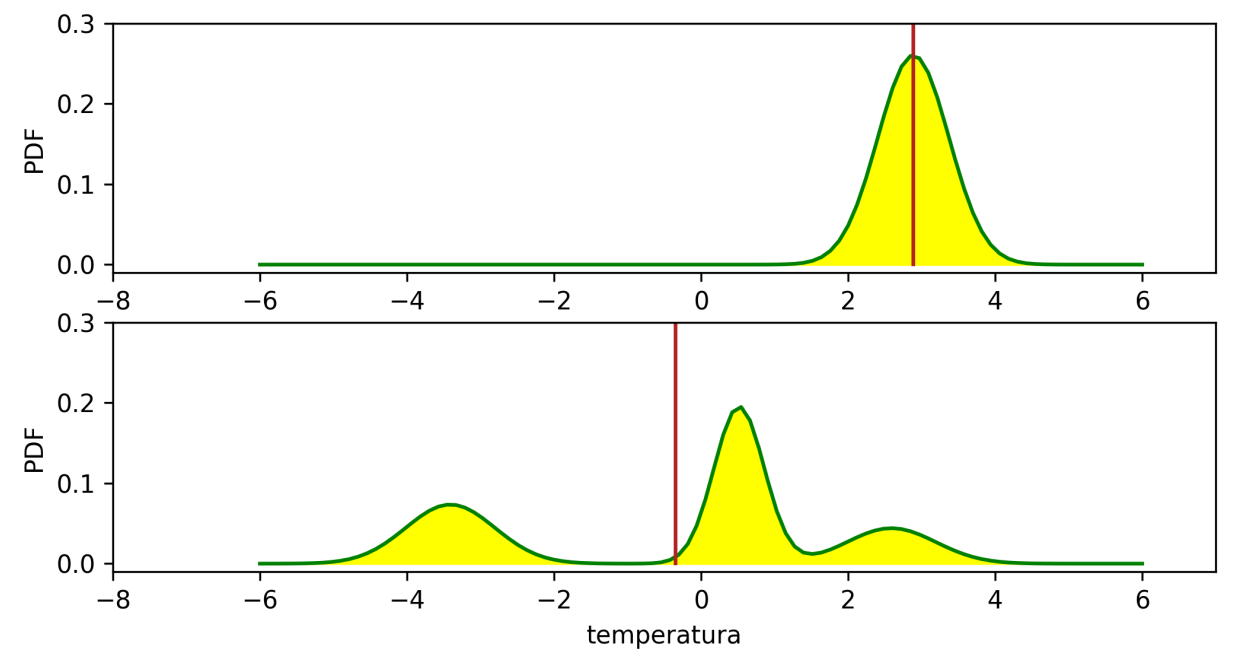

Figura 13.14: Dos PDF de temperatura distintas, arriba una PDF en la que el promedio, en rojo, es una temperatura plausible y otra PDF, abajo, en la que el promedio no es una temperatura plausible porque no está contenida en los intervalos en que la PDF presenta probabilidades no nulas (ver texto).

Por lo tanto, se desaconseja encarecidamente en las guías de predicción utilizar el promedio del SPC si no se hace con extremo cuidado. Sin embargo, el promedio del SPC se dibuja a menudo en mapas junto con la desviación estándar, esta última como medida de dispersión, para ayudar a entender el papel de la dispersión en el flujo atmosférico diario, lo que llamamos la situación atmosférica (puede verse un ejemplo en la Figura 13.16 en la página 182). Ilustraremos esta importante idea de dos modos diferentes.

El primero es un ejemplo relativamente cotidiano, rescatando el ejemplo descrito en la sección 12.3 en la página 159, que se ilustraba en la Figura que reproducimos de nuevo aquí 12.3 en la página 159. En aquel ejemplo se trataba de dar una predicción sencilla de temperatura en un jardín con una estimación de la temperatura inicial y un modelo que calcula la temperatura dentro de 24 horas. Se estimaba una PDF de temperatura inicial y otra PDF que da una estimación de la temperatura prevista en 24 horas, ambas PDF ilustradas ahora con más detalle, arriba y abajo respectivamente, en la Figura 13.14.

Promedio o valor esperado de la temperatura dada su PDF. La curva verde de la Figura 13.14 es la PDF, es decir, la distribución de probabilidad de temperatura que denotamos por $f(T)$, que cumple $\int_{-\infty}^{+\infty} f(T) d T=1$.
El eje vertical indica la probabilidad de que se de la temperatura indicada en el eje horizontal. La probabilidad acumulada propiamente dicha es el área bajo la curva, en amarillo. La recta vertical roja indica el promedio de la PDF, es decir, la integral $\int_{-\infty}^{+\infty} T f(T) d T$. Es importante observar que, si la PDF es simétrica y monomodal como en el ejemplo superior, entonces el promedio del SPC es una temperatura plausible, consistente, porque está dentro de la PDF y que, sin embargo, en muchos casos como en el ejemplo inferior en que la PDF está relativamente deformada (trimodal) con respecto a la PDF inicial, el promedio del SPC no es una temperatura plausible, consistente, porque no está dentro de la PDF: como hemos insistido anteriormente, esta propiedad es de suma importancia para el uso de predicción probabilista en meteorología.

El segundo modo de ilustrar la idea será mediante el atractor de LORENZ (sec. 5.2.3 en la página 59) en la Figura 13.15 en la página siguiente. El hecho de que el promedio entre varios puntos no esté necesariamente contenido en el atractor conduce a que el promedio del SPC no sea necesariamente una situación meteorológica consistente. Desde el punto de vista práctico, las situaciones representadas con puntos verdes en el atractor, corresponden a dos sellos (sec. 27.2.1 en la página 402) del SPC, marcados con rectángulos verdes en la figura. El promedio, punto negro, no se corresponde con ningún sello. 

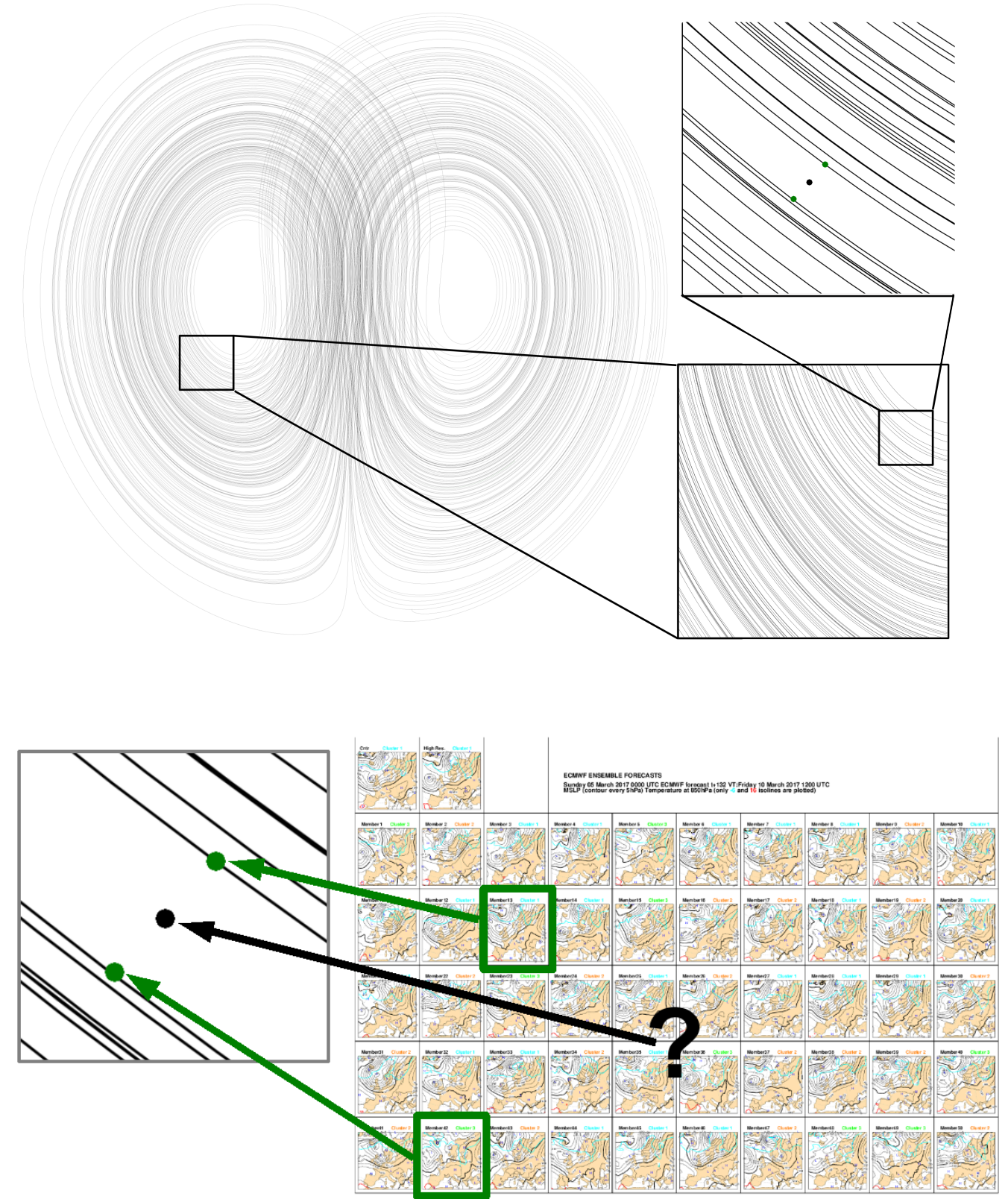

Figura 13.15: Arriba podemos ver dos ampliaciones sucesivas de una región del atractor de LORENZ. Abajo se amplía aún más la región de interés. Los puntos verdes representan predicciones de dos miembros del SPC para un momento dado. El promedio entre ambas, el punto negro no es, en este caso y tampoco en general, una situación o estado plausible pues no está contenido necesariamente en el atractor.

No obstante, a pesar de lo dicho sobre el promedio del SPC, éste cumple una propiedad estadística que también es de suma importancia, pero por otros motivos: individualmente, presenta mejor calidad determinista que cualquier miembro del SPC tomado por separado $\mathrm{o}$, enunciado de otro modo, el valor esperado de un campo previsto dada su PDF es una predicción de más calidad, habilidad, destreza o pericia (sec. 15.2.3 en la página 211) que los miembros individuales del SPC
[41]. Esta propiedad está relacionada con el hecho de que el promedio filtra lo poco probable, mostrando los rasgos más probables de la PDF y resulta de suma utilidad en el contexto de la verificación de SPC (sec. 15.7 en la página 221). En cualquier caso, el objetivo principal y el uso primordial de un SPC no puede, no debe ser, utilizar el promedio del SPC como predicción determinista per se. 


\subsubsection{Medidas de dispersión}

Hemos presentado en primer lugar las medidas de centralización, una primera propiedad de las distribuciones de probabilidad o estadísticas que nos describe su naturaleza de forma, quizá excesivamente, resumida. Presentamos ahora la dispersión, otra propiedad que completa la información resumida sobre una distribución: la centralización no es suficiente, pues hay distribuciones muy distintas con la misma media, mediana o moda. Así como la centralización resume los datos centrales o alguna representación adecuada de los mismos, la dispersión indica cuán esparcidos o dispersos están los datos de la distribución. En términos muy visuales, a más dispersión, más «esparcimiento» y menos «apelotonamiento». En la práctica, existen diferentes medidas estadísticas para la dispersión de una distribución. Entre las más usuales y sencillas tenemos la desviación estándar $[66,71]$ y el rango intercuartílico [71].

Desviación estándar y varianza. En SPC, un modo simplificado de representar la incertidumbre es restringirse a la dispersión. La desviación estándar de la PDF, relacionada con el momento de orden dos, cuantifica la desviación de los miembros del SPC con respecto al promedio del mismo, con las mismas unidades que la variable prevista y se utiliza usualmente como medida de dispersión [66, 71]. La desviación estándar $\sigma$ es la raíz cuadrada de la varianza $\sigma=\sqrt{\sigma^{2}}$. La expresión teórica de esta última para variables continuas es:

$$
\sigma^{2}=\int_{-\infty}^{+\infty}(x-\bar{x})^{2} f(x) d x
$$

donde $x$ es la variable aleatoria, $\bar{x}$ su promedio y $f(x)$ la función de densidad de probabilidad. En el caso de variables discretas, que es la expresión más utilizada en computación en la práctica:

$$
\sigma^{2}=\frac{1}{N-1} \sum_{i=1}^{N}\left(f_{i}-\bar{f}\right)^{2}
$$

donde $f_{i}$ es el valor previsto por el miembro $i$ y $\bar{f}$ es el promedio del SPC, es decir, el promedio de las $N$ predicciones. Esta medida puede calcularse para cada punto de malla, cada alcance predictivo y cada variable meteorológica. $\sigma$ puede interpretarse como una estimación del error de la predicción determinista de modo que, cuanto más alta la desviación, es decir, la dispersión, más incierta es la predicción.
El $N-1$ del denominador en la ecuación 13.5 corresponde a la desviación estándar insesgada. Una medida adimensional de dispersión es el coeficiente de variación:

$$
\sigma_{v}=\frac{\sigma}{\bar{x}}
$$

Rango intercuartílico, inter quartile range, IQR. Viene dado por $[36,71]$ :

$$
I Q R=q_{75}-q_{25}
$$

donde $q_{75}$ y $q_{75}$ son, respectivamente, los percentiles 75 y 25 de la distribución. El IQR es más robusto y más resistente que la desviación estándar. Más robusto, por que no es sensible a la presencia de valores atípicos (outliers). Y más resistente, por que no depende de asumir una distribución de probabilidad subyacente u otra. A pesar de ser ello, $\sigma$ se utiliza usualmente en centros operativos de SPC.

Dispersión para el ejemplo de Sevilla. Sigamos con el caso de temperatura prevista en Sevilla para el 8 de agosto de 2017 a las 18 UTC, con valores previstos: $30,30,30,30,31,31,31,31,31,31,32,32$, 32, 32, 32, 33, 33, 34, 34, 35, 36. La desviación típica (sec. 13.6.5) es, aproximadamente, $1.6^{\circ} \mathrm{C}$. Los percentiles $p_{25}=31$ y $p_{75}=33$, por lo que el rango intercuartílico es $I Q R=p_{75}-p_{25}=33-31=2{ }^{\circ} \mathrm{C}$.

Robustez. Comparación de media con mediana y desviación típica con rango intercuartílico. Imaginemos una predicción probabilista, similar a la del ejemplo de Sevilla, pero con un valor atípico debido a un modelo que ha cascado. Los valores previstos ahora son $10,30,30,30,31,31,31,31,31,31,32,32,32,32$, $32,33,33,34,34,35,36$. Contrastemos las medidas comentadas en uno y otro caso.

\begin{tabular}{|c|c|c|}
\hline distribución & original & con un outlier \\
\hline \hline media & 32.0 & 31.0 \\
\hline mediana & 32.0 & 32.0 \\
\hline desviación típica & 1.6 & 5.0 \\
\hline IQR & 2.0 & 2.0 \\
\hline
\end{tabular}

Se comprueba claramente que tanto la media como la desviación típica son sensibles a los valores atípicos, mientras que la mediana y el rango intercuartílico son más robustos: su valor no cambia en presencia de un outlier. 
Relación entre dispersión e incertidumbre. En este contexto, los SPC son una herramienta idónea para estimar la evolución temporal de la PDF en forma de un conjunto de estados atmosféricos individuales seleccionados, cada uno de ellos físicamente plausible. $L a$ dispersión de estos estados da una información explícita, cuantitativa y detallada de la incertidumbre en la predicción [66, 67] y por ende sobre la predecibilidad. Es decir, cuanta más (menos) dispersión, menor (mayor) es la predecibilidad. Este hecho es un punto de ruptura con respecto a los modelos deterministas.

\section{Crecimiento de la dispersión. Los SPC no son pro-} pios del medio plazo, también son importantes en el corto plazo. En los años 90 en AEMET se comenzó utilizando los SPC para el medio plazo, al principio como apoyo al modelo determinista de mayor resolución, asumiendo que la incertidumbre crece significativamente a partir del medio plazo, pero no en el corto. Más tarde se sistematizó la evaluación metódica de la dispersión, mediante grupos y supergrupos, y la predicción puramente probabilista con mapas de probabilidad, etc., pero se seguía asociando los SPC al medio plazo. Actualmente se acepta al fin que la incertidumbre crece significativamente o no dependiendo del flujo atmosférico de modo que, aunque la incertidumbre sinóptica a menudo empieza a ser significativa en el medio plazo, hay numerosos días del año o situaciones en que la incertidumbre en escala convectiva es crucial y, por tanto, es significativa desde un plazo muy temprano. Se trata de un problema de escalas: según la escala de interés, el crecimiento de la dispersión y la incertidumbre puede o no ser significativo.

Mapas de promedio y dispersión. En este libro insistimos repetidas veces en que el promedio del SPC no es necesariamente una situación meteorológica plausible. Sin embargo, el promedio suele dibujarse acompañando a la dispersión en unos mapas que tienen suma utilidad, para predicción operativa, como orientación sobre áreas con poca predecibilidad a priori. En la Figura 13.16 se muestra un ejemplo de predicción de altura geopotencial del SPC ECENS sobre Europa, válido para el 09-03-2017 a las 00 UTC, pasada de 05-03-2017 a las 00 UTC, alcance de T+96. La altura geopotencial es un parámetro dinámico que permite describir convenientemente el comportamiento atmosférico en escala sinóptica. La desviación estándar, como medida de dispersión, se presenta en colores morados, mientras que el promedio del ensemble se dibuja en isohipsas, es decir, isolíneas de altura geopotencial. La desviación estándar está representada en las mismas unidades. Podemos ver que se prevé más dispersión sobre las áreas de Túnez y del mar Egeo, a ambos lados de una DANA mediterránea, dispersión asociada a la incertidumbre en la posición de la misma. Así mismo se prevé más dispersión en el lado occidental de una vaguada en Europa del norte, asociada a la incertidumbre en la magnitud de la profundidad de la misma. Estos mapas se abordan con detalle en la sección 27.5 en la página 412. La dispersión puede evaluarse mediante otra aproximación, que es la agrupación, vista con excelente detalle en la sec. 27.4 en la página 406.

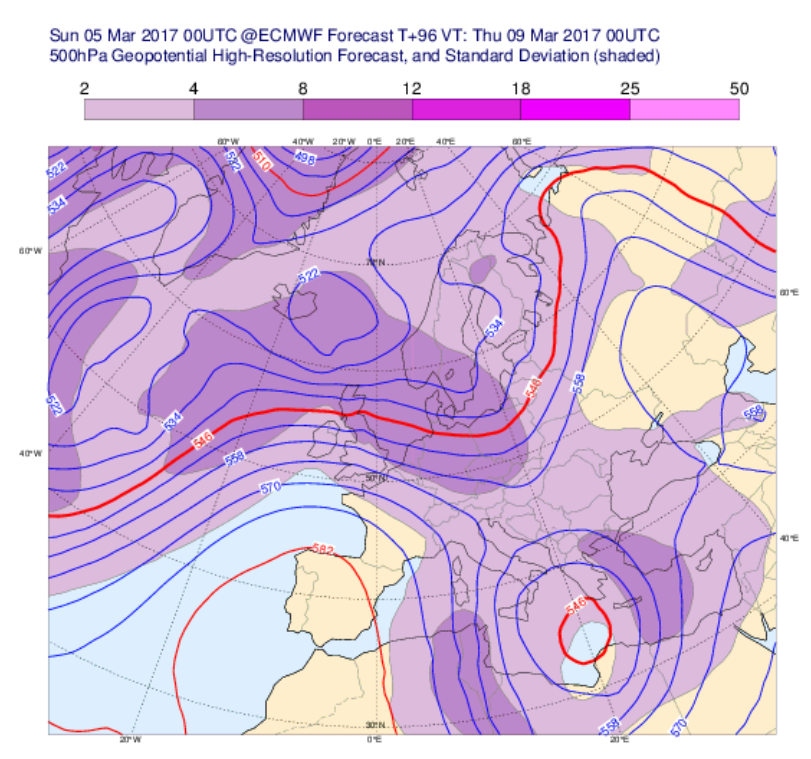

Figura 13.16: Mapa de promedio y dispersión del SPC ECENS sobre Europa (ver texto). 


\subsubsection{Medidas de posición}

Después de presentar las medidas de centralización y dispersión, presentamos las de posición que, a menudo, son indicadores más robustos y resistentes de ciertas propiedades, como ya hemos ido adelantando. Si ordenamos la distribución de valores previstos (seguimos, cómo no, con el ejemplo anterior de Sevilla), hay unos valores especiales a tener en cuenta:

El mínimo y el máximo delimitan todos los valores. El mínimo deja a su derecha el $100 \%$ de los valores y el máximo deja a su izquierda el $100 \%$ de los valores

Mediana es el nombre dado al valor central. Deja a su izquierda el $50 \%$ de los valores y a su derecha el otro $50 \%$ (cuando el número de valores es par, no hay valor central, y se hace el promedio de los dos valores centrales).

Percentiles son aquellos valores que dividen a la distribución en partes dadas. Por ejemplo, el percentil 25 deja a su izquierda el $25 \%$ de los valores y el percentil 75 deja a su izquierda el $75 \%$ de los valores. Vemos, por ejemplo, que la mediana es el percentil 50, que el mínimo es el percentil 0 y que el máximo es el percentil 100.

\footnotetext{
$34,35,36$. Tenemos que:

- Mínimo $=p_{0}=30$

- Máximo $=p_{100}=36$

- Mediana $=p_{50}=32$

- Percentil $25=p_{25}=31$

- Percentil $75=p_{75}=33$
}

Medidas de posición en la predicción probabilista para Sevilla. En el ejemplo anterior de la temperatura prevista para Sevilla, recordemos que los valores previstos eran (estaban ya ordenados) 30, 30, 30, 30, 31, 31, 31, 31, 31, 31, 32, 32, 32, 32, 32, 33, 33, 34,

\subsubsection{Valores atípicos (outliers)}

Los conjuntos de datos pueden incluir, ocasionalmente, valores denominados atípicos. Los valores atípicos, por diversas razones, son valores que no son tenidos en cuenta por resultar sospechosos: pueden ser demasiado altos, demasiado bajos, quedan en general fuera del rango de valores considerados aceptables.
Valores atípicos en la predicción probabilista para Sevilla. En el ejemplo anterior de la temperatura prevista para Sevilla, podríamos tener valores atípicos si el conjunto de miembros fuera, por ejemplo: 10 , $30,30,30,31,31,31,31,31,31,32,32,32$, 32, 32, $33,33,34,34,35,36$. Vemos que hay un 10 en lugar de un 30 en el primer lugar de la lista. Esos $10^{\circ} \mathrm{C}$, a priori, son sospechosos de ser un valor atípico.

En ocasiones la sospecha puede requerir una exploración, para contrastar la plausibilidad del dato, que eventualmente podría ser posible y tendríamos que aceptarlo. Ese contraste puede ser una exploración de las salidas del modelo correspondiente a ese miembro, es decir, buscar el origen del dato. En algunos ámbitos el contraste es de naturaleza simplemente estadística: pueden por ejemplo, rechazarse todos aquellos valores que queden fuera del intervalo $\left[Q_{1}-1,5 I Q R, Q_{2}+1,5 I Q R\right]$, siendo $Q_{1}$ y $Q_{2}$ los percentiles $25 \%$ y $75 \%$, respectivamente y siendo $I Q R=Q_{2}-Q_{1}$ el llamado rango intercuartílico. El IQR comprende el $50 \%$ central de los datos de la distribución, y el intervalos, más grande, $\left[Q_{1}-1,5 I Q R, Q_{2}+1,5 I Q R\right]$ comprende un abanico de datos que, en una buena parte de casos, puede ser considerado como el abanico realista de datos posibles. Todos los datos que queden fuera de ese abanico pueden descartarse y ser considerados valores atípi$\cos$.

\subsubsection{Diagramas de caja (boxplots)}

Los denominados métodos exploratorios o descriptivos (ver sec. 15.2.2 en la página 210) permiten, precisamente, explorar los datos de una distribución en perspectiva, en conjunto, para percibir algunas de sus propiedades antes de comenzar a estimarlas mediante métodos más refinados. Los diagramas de caja o boxplot representan valores representativos de la distribución y son tremendamente útiles para hacerse una idea de la distribución en conjunto, sin profundizar en sus detalles. El diagrama de caja es un modo rápido y sencillo de explorar un conjunto relativamente amplio de números de forma muy visual, ofreciendo una idea de una distribución compleja de valores, ocasionalmente con un gran número de ellos. La Figura 13.21 en la página 187 muestra las características de un boxplot, mientras que la Figura 13.18 en la página siguiente muestra varios ejemplos de boxplots, ilustrando además el impacto de outliers en una distribución. 


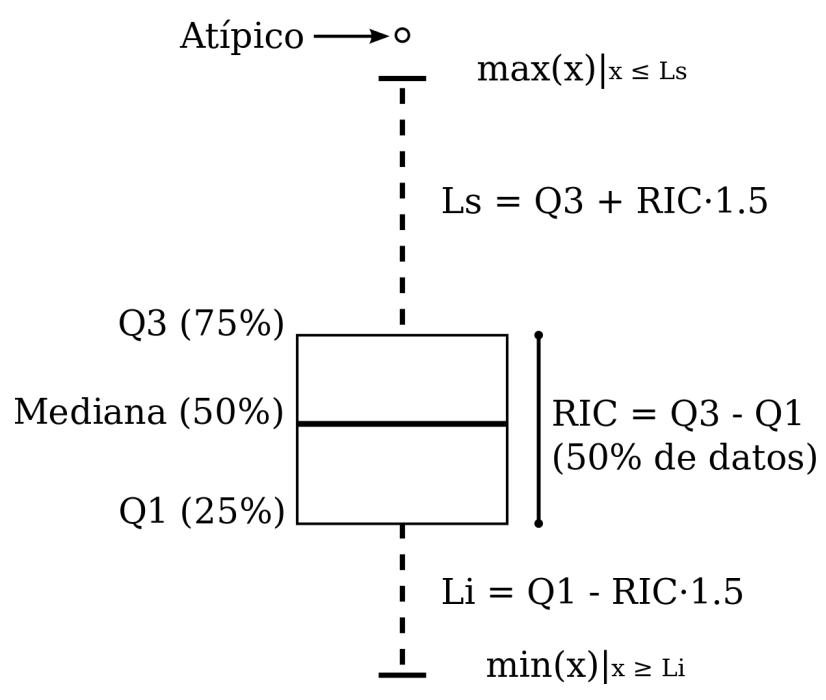

Figura 13.17: Elementos de un diagrama de caja o boxplot. La caja principal contiene el $50 \%$ de los valores de la distribución, desde el percentil $25 \%$ (Q1), pasando por la mediana (percentil 50\%), hasta el percentil $75 \%$, es decir, el denominado rango intercuartílico (RIC o $I Q R$, de sus siglas en inglés). Los bigotes (whiskers) abarcan, opcionalmente (Figura 13.19 en la página siguiente), desde el mínimo hasta Q1 y desde el Q2 hasta el máximo. Otra opción (adoptada en esta figura), es dejar aparte los valores atípicos (outliers), de modo que los bigotes llegan sólo hasta unos límites superior e inferior reducidos, en particular $Q_{1}-1,5 I Q R$ por abajo y $Q_{2}+1,5 I Q R$ por arriba. CC-BY-SA-3.0 https: // commons. wikimedia. org/wiki/File: Boxplot. svg.
Es conveniente, en general, complementar los boxplot con otros métodos exploratorios y, además, con métodos de otras naturalezas, como por ejemplo los métodos orientados a medidas (scores) y orientados a distribuciones (ver secs. 15.2.1 en la página 210).

\subsubsection{Ejemplos sencillos de predicciones SPC}

Cada predicción puntual, en el espacio y en el tiempo, de un SPC es, así pues, una distribución de frecuencias que indica los valores más probables para la variable meteorológica en cuestión. Conocer las características generales de esa distribución es vital para realizar una buena predicción probabilista, por lo que herramientas como los boxplot, en forma de EPSgramas (sec. 27.8.1 en la página 425) o las CDF, en forma de mapas de probabilidad (sec. 27.6.1 en la página 416), son de crucial importancia para un buen equipo de predicción del tiempo. Diferentes distribuciones tienen diferentes interpretaciones. ¿Es simétrica? ¿Si es asimétrica, hacia qué lado tiende? ¿Tiene mucha o poca dispersión? ¿Sabemos qué variable estamos tratando, para chequear la consistencia de nuestras afirmaciones? En la Figura 13.19 en la página siguiente presentamos seis ejemplos ilustrativos de distribuciones con diferentes propiedades.

\section{Ejemplos de distribuciones con histograma de frecuencia y diagrama de caja}
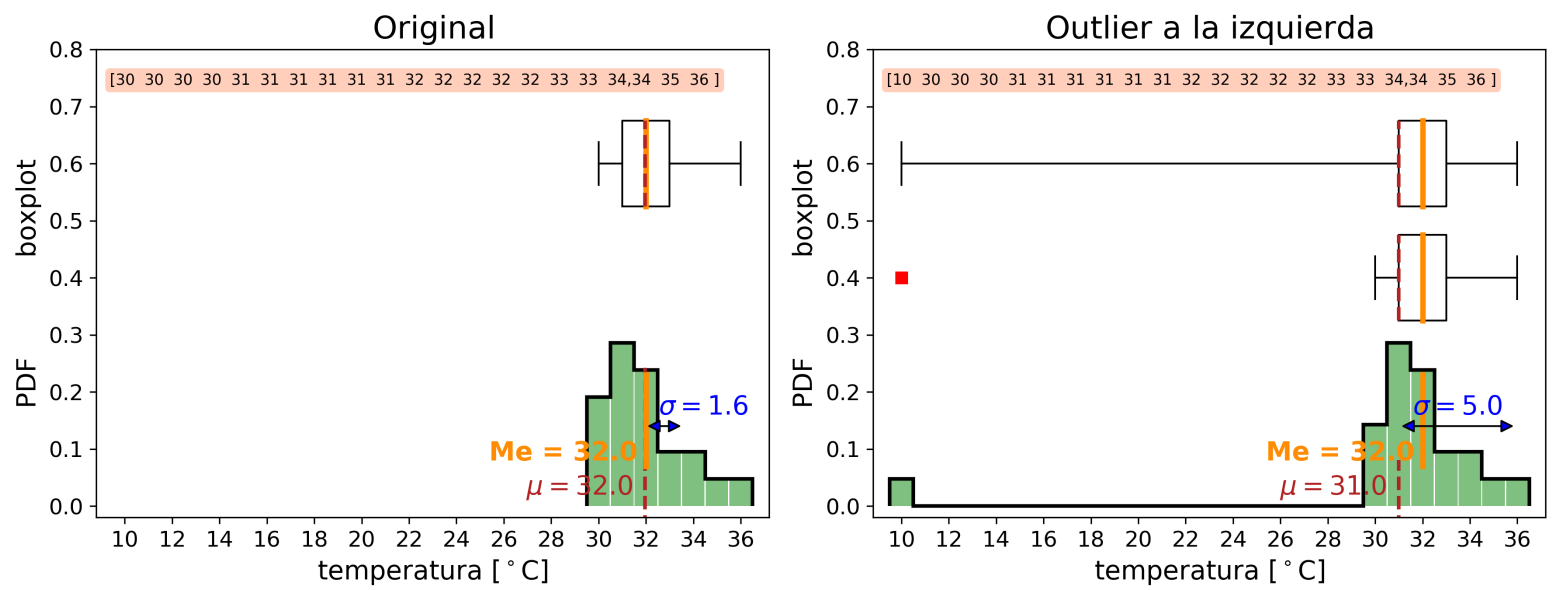

Figura 13.18: Impacto de los valores atípicos en una distribución, en particular en la del ejemplo de la previsión de temperatura para Sevilla el 8 de agosto de 2017 a las 12 UTC. A la izquierda, la distribución original. A la derecha, la misma pero sustituyendo un 30 por un 10, valor atípico. Para cada predicción (o distribución de valores), mostramos ( $i$ ) en un cuadro de color salmón la distribución de valores previstos; (ii) el diagrama de caja (boxplot) de esos valores con la mediana en naranja y la media en rojo, la caja abarcando el rango intercuartílico (IQR) y los bigotes abarcando desde el mínimo hasta el máximo; (iii) el histograma de frecuencias relativas de esos mismos valores, con el mismo eje horizontal. En la parte derecha pueden observarse dos variantes de boxplot, la inferior dejando el outlier «fuera» marcándolo en rojo. 


\section{Ejemplos de distribuciones con histograma de frecuencia y diagrama de caja}
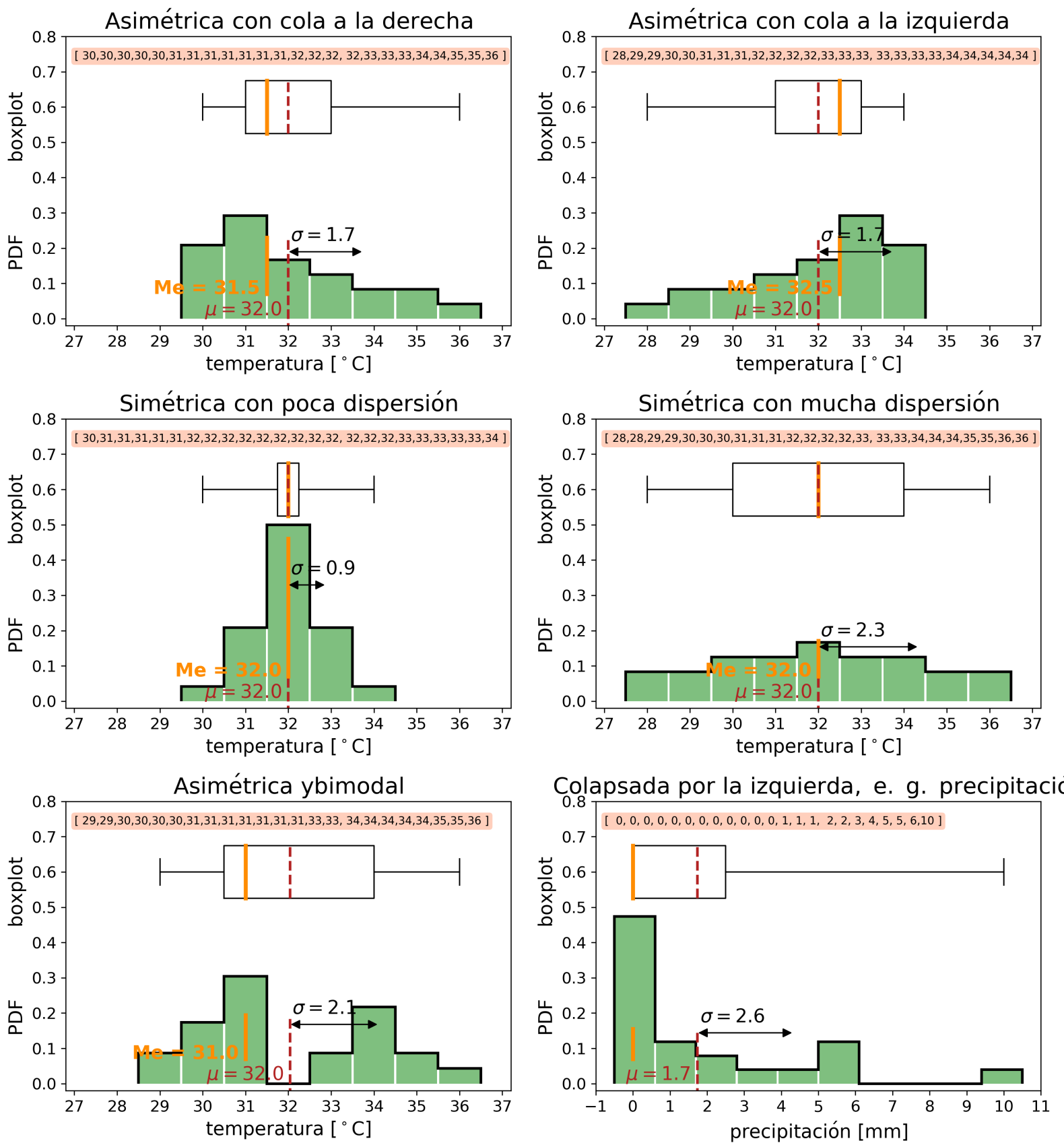

Figura 13.19: Ejemplos de predicciones SPC en un punto geográfico e instante concreto (e. g. Sevilla el 8 de agosto de 2017 a las 14 UTC). Cada predicción es un conjunto o distribución de valores, que puede representarse de muchos modos. Para cada predicción, mostramos (i) en un cuadro de color salmón la distribución de valores previstos; (ii) el diagrama de caja (boxplot) de esos valores con la mediana en naranja y la media en rojo, la caja abarcando el rango intercuartílico (IQR) y los bigotes abarcando desde el mínimo hasta el máximo; (iii) el histograma de frecuencias relativas de esos mismos valores, con el mismo eje horizontal. Presentamos, así, seis predicciones de diferente naturaleza, cada una con sus valores, su diagrama de caja y su histograma; las cinco primeras son de temperatura y la última es de precipitación. Para la temperatura la media es de 32.0 grados en todos los casos, para ilustrar la idea de que la media es un resumen incompleto de la distribución. Fila superior: dos distribuciones asimétricas, con cola a la derecha y con cola a la izquierda. La media y la mediana no coinciden y la caja del boxplot se estira Fila central: dos distribuciones simétricas, una concentrada y otra dispersa. La media y la mediana coinciden, una desviación típica es mucho menor que la otra, correspondiendo a su dispersiones respectivas. Fila inferior izquierda: una distribución asimétrica y bimodal. Obsérvese cómo la media es un valor delicado pues no se corresponde con ningún valor previsto realmente. Fila inferior derecha: predicción de precipitación que, típicamente, contiene muchos ceros, resultando una distribución tan asimétrica que está colapsada a la izquierda, en el cero, y su boxplot sólo presenta de la mediana hacia la derecha, pues el valor es cero para el mínimo, el Q1 y la mediana. 

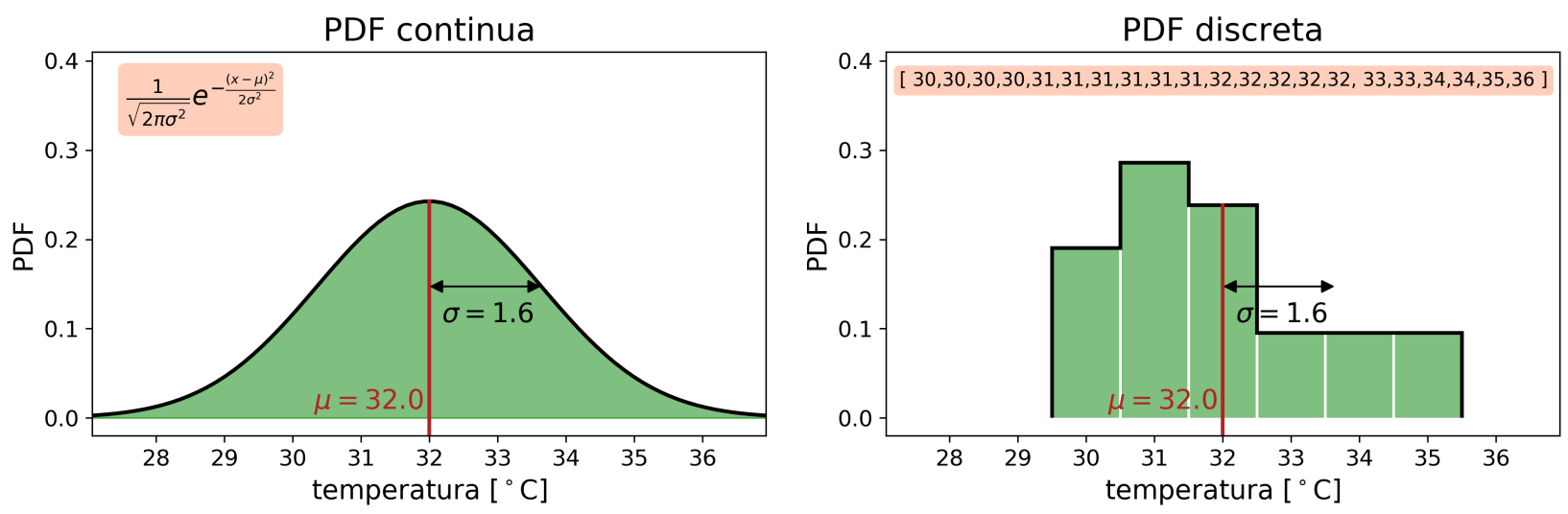

Figura 13.20: Izquierda: distribución continua gaussiana con $\mu=32,0$ y $\sigma=1,6$. Derecha: histograma que muestra, siguiendo con el ejemplo, la distribución discreta de temperatura a 2 m prevista para Sevilla el 08-08-2017 a las 18 UTC por un hipotético SPC (en el punto de malla más cercano a Sevilla). Los valores del promedio y la dispersión para esta previsión son, respectivamente, $\mu=32,0$ y $\sigma=1,6$. En el caso de que quisiéramos ajustar esta distribución discreta a una distribución gaussiana contiua, usaríamos precisamente la distribución mostrada a la izquierda, partiendo de los valores de $\mu$ y $\sigma$ dados, lo cual es una simplificación.

\subsubsection{Ajuste de una distribución}

Sigamos con nuestro ejemplo de la temperatura prevista para Sevilla mediante una predicción probabilista de 21 miembros: 30, 30, 30, 30, 31, 31, 31, 31, 31, $31,32,32,32,32,32,33,33,34,34,35$, 36. Este hipotético SPC consta de 21 miembros. Cuantos más miembros, más alta será la resolución probabilista de su PDF. La resolución probabilista tiene ventajas que se abordarán con detalle en el capítulo sobre verificación (cap. 15 en la página 207). De momento, baste decir que un SPC con más miembros que otro es más susceptible de capturar una situación atmosférica poco probable. En la Figura 13.20 derecha se muestra en un histograma de frecuencias esta distribución de 21 valores previstos. Si sólo pudiéramos disponer del promedio y la desviación de esa distribución de valores, esa riqueza de información quedaría resumida en dos cantidades: $\mu=32,0, \sigma=1,6$. En ocasiones, se pretende ajustar una distribución discreta a una continua por diversas razones, aunque se disponga del conjunto de valores discretos. En esos esos casos se suele recurrir a alguna hipótesis ad hoc o alguna simplificación oportuna. Por ejemplo, podríamos asumir que la distribución poblacional de la temperatura del ejemplo es aproximadamente gaussiana (o normal) y utilizar una PDF continua teórica con el mismo promedio y desviación que la real, para obtener un ajuste de la misma. Por tanto, estaríamos perdiendo información, simplificando al quedarnos sólo con el promedio y la desviación típica, a cambio de disponer de una distribución continua, que puede ser útil para otros fines. Tomando $\mu=32,0, \sigma=1,6$ y aplicando la ec. 13.8, resulta la Figura 13.20 izquierda. Asumiendo que la variable $x$ sigue esta distribución, podemos inferir información sobre el comportamiento de $x$. Podemos decir que hay un valor central alrededor del cual se distribuyen los valores simétricamente. En ese contexto, $\sigma$ es una medida de cuánto se desvían los valores respecto de $\mu$, una medida de dispersión, que ya hemos abordado anteriormente. Podemos, también, pensar en $\sigma$ como un error o incertidumbre media que tendríamos si aproximamos un valor $x$ mediante la media $\mu$. La distribución real no es exactamente gaussiana, pero sí lo es, en general, aproximadamente. Según el contexto, es conveniente trabajar con la distribución conocida de valores (Figura 13.20, derecha), nuestro primer ejemplo o con un ajuste mediante reconstrucción paramétrica (Figura 13.20, izquierda), nuestro segundo ejemplo.

Distribución normal o gaussiana. La PDF gaussiana general sigue la expresión:

$$
P D F(x)=\frac{1}{\sqrt{2 \pi \sigma^{2}}} e^{-\frac{(x-\mu)^{2}}{2 \sigma^{2}}}
$$

donde $\sigma$ es la desviación estándar y $\mu$ es la media, ambas de la población, mientras que $x$ es la variable aleatoria, en este caso la temperatura. 


\section{PDF, CDF y probabilidad de superación de umbral}
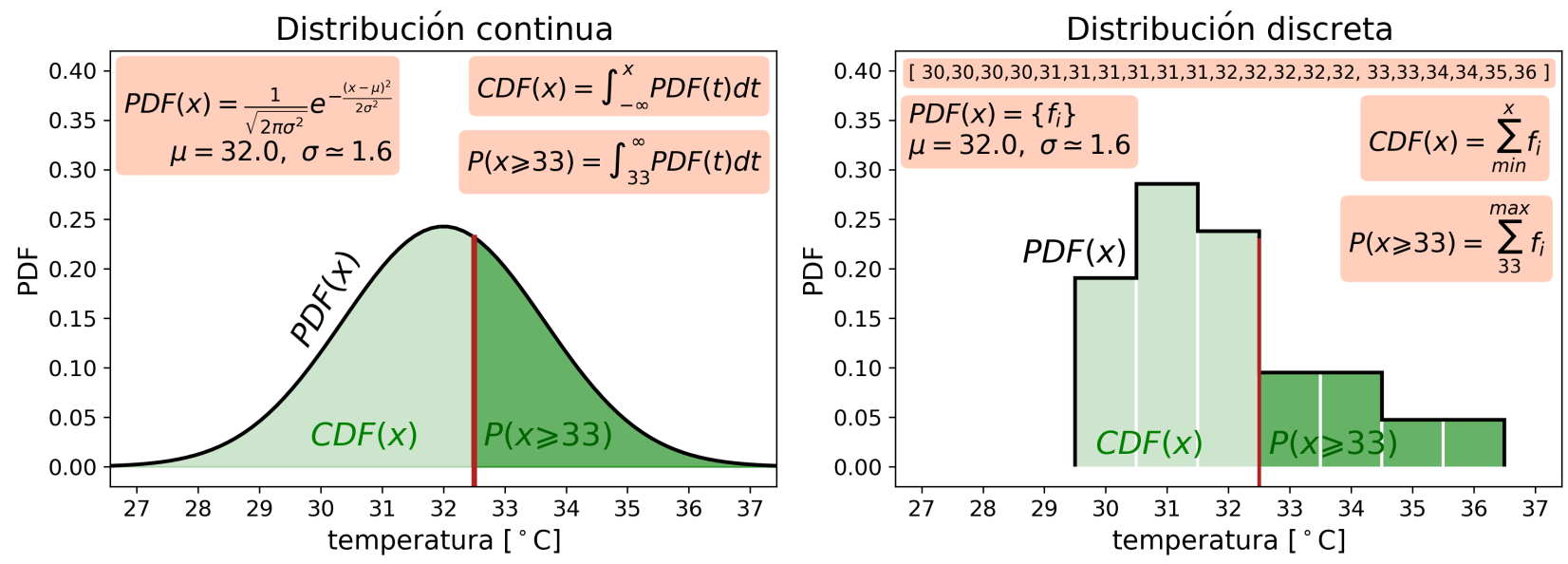

Figura 13.21: Para dos tipos de distribuciones figuradas con datos hipotéticos de temperatura, continua (izquierda) y discreta (derecha) mostramos los conceptos de CDF, PDF y probabilidad de superación de un umbral meteorológico. En ambos casos el promedio es de $32{ }^{\circ} \mathrm{C}$ y la desviación típica de $1.6{ }^{\circ} \mathrm{C}$. La distribución continua resulta ser simétrica. Su PDF $(x)$ es la curva negra, una campana de GAUSS. Su CDF $(x)$ es el área bajo la PDF hasta llegar al umbral $x$, en verde claro. La probabilidad de que la variable supere el umbral x es el área bajo la PDF desde $x$ hasta el final. La distribución discreta resulta ser discontinua, con la cola hacia la derecha. La PDF (x), la CDF (x) son conceptos análogos al caso continuo.

\subsubsection{Computación de la probabilidad: PDF, CDF y percentiles}

Función densidad de probabilidad, PDF. Una distribución de probabilidad o de frecuencia nos brindan, respectivamente, la probabilidad para cada valor o la frecuencia empírica para intervalo de valores de la variable aleatoria $x$. El término Probability Density Function o Probability Distribution Function (PDF), se refiere a la distribución de probabilidad o de frecuencia indistintamente, relajando los criterios: dado un valor de $x$ o, alternativamente, una clase, $P D F(x)$ proporciona la probabilidad de que tenga lugar el suceso $x$. En el caso de la distribución de probabilidad, en forma continua , la representación gráfica (Figura 13.21 izquierda) es una función real de variable real. Se ha de cumplir la denominada condición de normalización:

$$
\int_{-\infty}^{+\infty} P D F(x) d x=1
$$

En el caso de la distribución de frecuencia, en forma discreta, la representación gráfica (Figura 13.21 derecha) es un histograma de frecuencias, donde la altura de la barra donde está cada $x$ indica la probabilidad del suceso correspondiente.
La condición de normalización en el caso discreto es:

$$
\sum_{i=1}^{N} P D F\left(x_{i}\right)=1
$$

Función acumulativa de probabilidad, CDF. Cuando nos interesa la probabilidad acumulada, es decir, la probabilidad de un conjunto acumulado de sucesos, entonces entra en juego el concepto de función de distribución acumulada o Cumulative Distribution Function (CDF). Si trabajamos con una distribución de probabilidad, la $C D F(x)$ se define en términos de una integral, la integral desde el principio del dominio hasta el valor $x$, que sería la probabilidad de que ocurra cualquier suceso hasta el valor $x$ :

$$
P(X<x)=C D F(x)=\int_{-\infty}^{x} P D F(t) d t
$$

Este valor coincide con el área bajo la $P D F(x)$ hasta la vertical correspondiente al valor $x$ (Figura 13.21 izquierda, área verde claro). Por otro lado, la probabilidad de que la variable aleatoria supere un umbral es precisamente la integral desde $x$ hasta el valor máximo, es decir, el área bajo la $P D F(x)$ desde $x$ hasta el final (Figura 13.21 izquierda, área verde oscuro):

$$
P(X>=x)=1-C D F(x)=\int_{x}^{\infty} P D F(t) d t
$$


Percentiles. La operación inversa de la CDF busca cuál es el umbral $u$ que da una probabilidad determinada $P$. Se definen así los percentiles $q_{i}$, que son aquellos valores de dividen la distribución en partes determinadas. E. g. $q_{25}$ viene dado por la expresión $P\left(X>q_{25}\right)=0,25$. En general:

$$
P\left(X>q_{i}\right)=\frac{i}{100}
$$

Otros percentiles importantes son la mediana $P(X>$ $\left.q_{50}\right)=0,50$ que divide la PDF en dos partes, los $q_{25} \mathrm{y}$ $q_{75}$ que permiten definir el IQR como $I Q R=q_{75}-q_{25}$ $\mathrm{y}$, finalmente, el máximo y el mínimo, $P\left(X>q_{100}\right)=0$ y $P\left(X>q_{0}\right)=1$, respectivamente.

Las salidas probabilistas de un SPC se computan a partir de la representación de la PDF, que viene dada por los miembros del SPC, tal como se ha venido mencionando anteriormente.

Distribuciones discretas. Computación de probabilidad y estadística en los SPC. Trabajando con un SPC de $N$ miembros, para cada punto de rejilla del $\mathrm{SPC}$, tenemos $N$ valores previstos de una variable dada, e. g. temperatura. Sin más información sobre la calidad, habilidad, destreza o pericia de cada miembro, asumimos la hipótesis de equiprobabilidad de LAPLACE y trabajaremos con una PDF discreta en la que todos los valores previstos son equiprobables. Con esas premisas, una estimación de la probabilidad de superar un umbral $u$ de temperatura en ese punto de rejilla está dada por [18]:

$$
P(X>u)=\frac{1}{N} \sum_{i=1}^{N} I\left(x_{i}>u\right), I\left(x_{i}\right)= \begin{cases}1 & x_{i} \geqslant u \\ 0 & x_{i}<u\end{cases}
$$

donde las $I\left(x_{i}\right)$ se denominan indicadores. Por construcción, las probabilidades calculadas son discretas $p \in\left\{\frac{1}{N}, \frac{2}{N}, \cdots, \frac{N}{N},\right\}$. La función inversa es la computación de percentiles, es decir, para una probabilidad dada $p$, cuál es el valor de la variable $x$ para el que $p=P(x)$ [11]. Con este mismo modelo discreto puede calcularse la media, la mediana, la varianza, la desviación típica, etc., tal como se ha descrito previamente. Añadiendo información, puede mejorarse la PDF mediante el proceso llamado calibración (ver sec. 13.7.1 en la página 190 y cap. 14 en la página 193), en cuyo caso la computación sería distinta. Para ello suele contrastarse la calidad de predicciones pasadas, usando medidas de calidad (sec. 15.2.3 en la página 212) y suele proporcionarse una PDF continua.
Estos conceptos y herramientas son de suma importancia en meteorología, pues están relacionados con la superación de umbrales críticos relacionados con los fenómenos meteorológicos adversos. La Figura 13.21 en la página anterior derecha muestra los términos equivalentes para una distribución discreta de frecuencias.

\subsubsection{Estimación del carácter extremo de la predicción}

Los fenómenos meteorológicos adversos (FMA) son de importancia capital en la predicción del tiempo y su adecuada previsión puede salvar vidas humanas y optimizar los recursos económicos y de protección civil. Los fenómenos extremos no son siempre adversos (y viceversa), pero hay una cierta relación. Uno de los mayores potenciales de los SPC es su gran capacidad para prever fenómenos extremos.

Las siglas EFI significan en inglés Extreme Forecast Index (Índice de predicción extrema). El EFI es una cantidad que puede calcularse usando el SPC y su climatología (llamada la climatología del modelo o, para ser más precisos, del SPC) que no es otra cosa que el «historial de predicciones». Para un lugar determinado, se compara la predicción probabilista (la famosa PDF, ver sec. 13.6 en la página 176) con ese historial, y se calcula un número, un índice, que dice «cuán extrema» es la predicción. Dentro de esta metodología se computan dos medidas ampliamente utilizadas: el Extreme Forecast Index, EFI y el Shift of Tail, SOT. Se desarrollan en detalle en la sección 27.7 en la página 419 sobre predicción del riesgo.

\subsubsection{Agrupamiento}

Para hacer tratable la información y resaltar partes predecibles, resulta útil normalmente agrupar todos aquellos miembros del SPC similares según una cierta norma, e. g. correlación entre campos, diferencia cuadrática, etc. El resultado de esta agrupación es un número reducido y manejable de escenarios representativos de los distintos grupos, que describen las partes más relevantes de una PDF. Este importante tema se aborda con gran detalle en la sección 27.4.1 en la página 406. 


\subsubsection{Mapas y gráficas}

Resultan imprescindibles para la predicción probabilista los diversos productos derivados de la CDF o su inversa (sección 13 en la página anterior). Habitualmente, se dibujan mapas de probabilidad de superación de umbrales, proporcionando una distribución espacial de probabilidad y, para la distribución temporal de probabilidad, son clásicos los EPSgramas que muestran, para una ubicación geográfica de interés, la evolución temporal de la PDF, usando el boxplot (sec. 27.8.1 en la página 425) como representación gráfica ideal, basado en los percentiles más básicos. Ver Figura 13.22. Estos productos generables a partir de los SPC reflejan la naturaleza probabilista de los mismos, visual y conceptualmente y se explorarán con detalle en el capítulo 27 en la página 401, así como algún aspecto concreto en la sección 17.5 en la página 271.
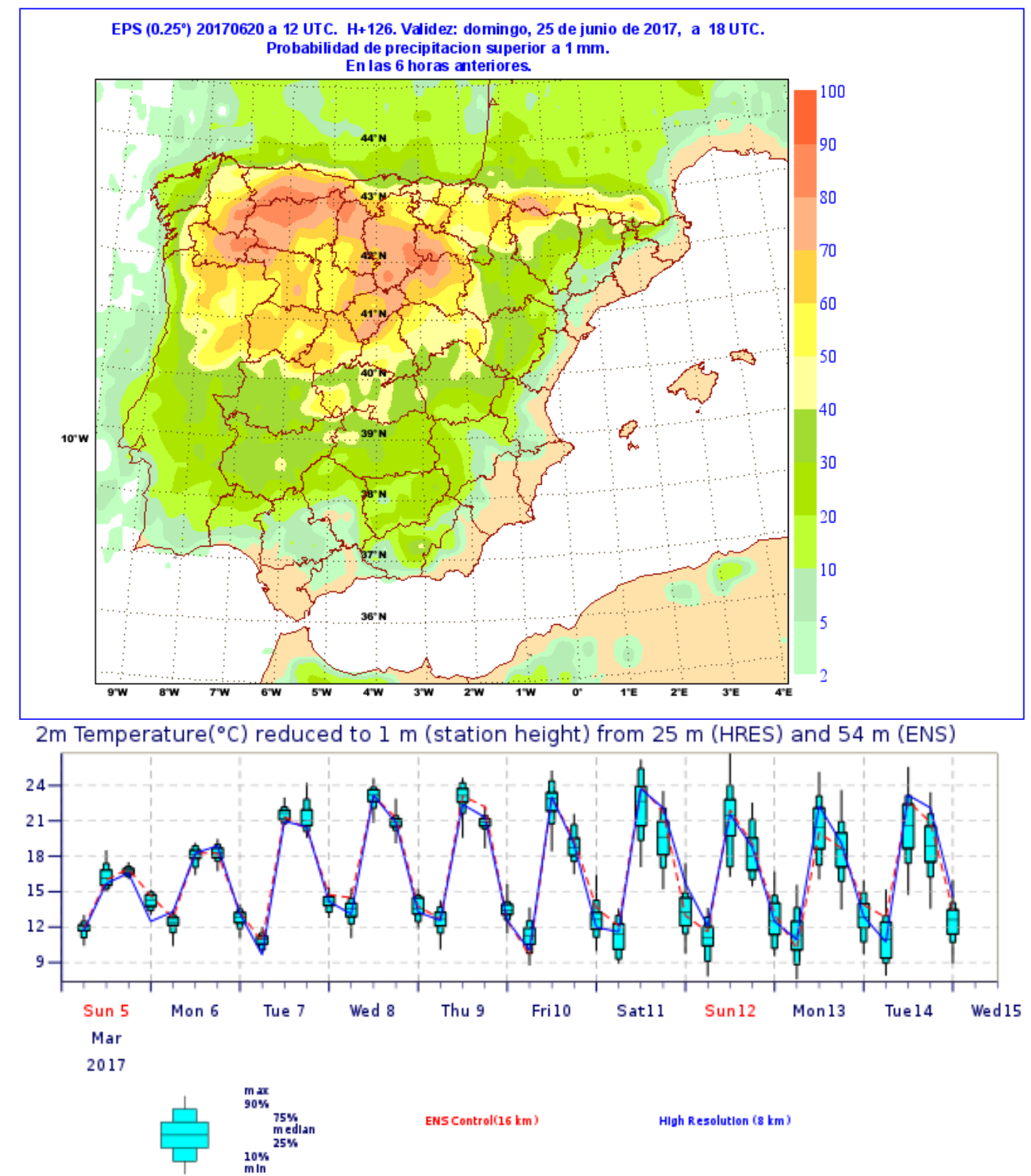

Figura 13.22: Dos representaciones de probabilidad distintas: a la izquierda, un mapa de probabilidades y, a la derecha, un EPSgrama (ver texto). 


\subsection{Visión crítica}

\subsubsection{Carácter discreto o continuo de la PDF}

En la sección 5.1.4 en la página 53 vimos que un conjunto de partículas con condiciones iniciales cercanas puede representarse por la región conexa que ocupa en el llamado espacio de fases, espacio de estados posibles de un sistema. El teorema de LiOUVILlE establece que dicha región mantendrá invariante su volumen a pesar de que se estirará y se encogerá a medida que cada partícula evolucione. Hemos visto en la sección 13.4 en la página 171 que la ecuación más general de FOKKER-PLANCK, o la de LiOUVILLE no pueden resolverse para modelos atmosféricos porque el número de grados de libertad o variables aleatorias es $10^{8}-10^{9}$. De modo que se utilizan los SPC para muestrear las incertidumbres debidas a las fuentes principales: condiciones iniciales, modelo y, en el caso de RCM, condiciones de contorno. Mediante estos SPC se puede estimar así una PDF del estado atmosférico en cada alcance predictivo de toda la evolución del sistema.

Ahora bien, usando las técnicas usuales esta PDF es discreta, mientras que la PDF atmosférica es, con toda probabilidad, continua. La pregunta incómoda surge de inmediato: al estimar una PDF continua con una PDF discreta ¿estamos explorando realmente el espacio de fases apropiadamente?. La respuesta es probablemente no. ¿Hasta qué punto puede representarse la PDF atmosférica, continua, mediante la PDF de un SPC, discreta? Este es uno de los problemas principales de toda esta disciplina de diseño de SPC.
Bayesian model averaging, BMA. Sin dar una respuesta teórica a este problema, algunos métodos de posproceso estadístico diseñan PDF continuas a partir de los datos brutos, discretos, del SPC. Un ejemplo es la técnica llamada promediado bayesiano del modelo, en inglés bayesian model averaging, BMA [5, 29, 55, 61]. El propósito de esta técnica no es hacer al SPC correspondiente consistente con LIOUVILLE, sino que es proporcionar una PDF con un rendimiento óptimo, para lo cual la convierte en continua. El método se discute en detalle en las secciones 14.1.2.0.1 en la página 195 y 21.6 en la página 319 y tiene un principio muy sencillo que se ilustra en la Figura 13.23. Partimos de un SPC de cinco miembros, de modo que tenemos cinco valores previstos $F_{i}$ en un lugar y momento dados. A cada uno de esos $F_{i}$ se le aplica, en primer lugar, una corrección de sesgo comparando las observaciones y predicciones de los últimos días y extrapolando el sesgo para la siguiente predicción. Después se construye una PDF individual continua para cada uno de los valores, por ejemplo, desplegando una gaussiana alrededor de cada valor central, con diferentes pesos y varianzas, que son parámetros estadísticos a determinar. Con el algoritmo estimationmaximitation, EM [13, 45, 56], en un proceso iterativo se optimiza una medida de verificación probabilista, el continuous ranked probability score, CRPS [28, 36, 71], que involucra a todos los miembros desde el punto de vista probabilista puro. Una vez determinados los pesos y las varianzas, ya tenemos una PDF predictiva continua. Este método, al capturar los valores atípicos (outliers) da una relación dispersión-error extremadamente buena. Sin embargo, el tratamiento de valores extremos sigue sin dar buen resultado [5], por lo que estos valores siguen siendo un problema.

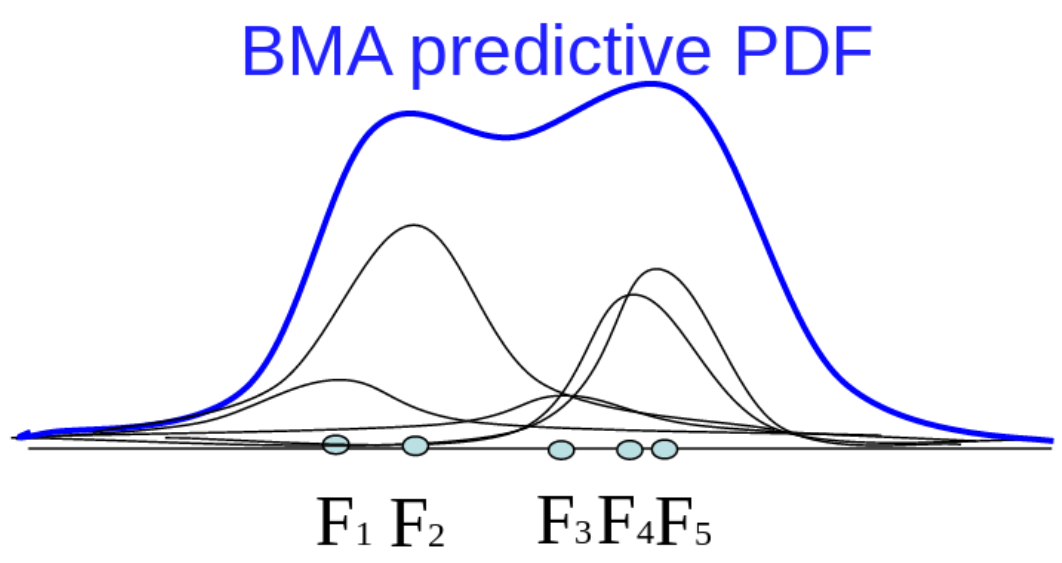

Figura 13.23: PDF discreta y PDF continua en la técnica BMA (ver texto). 


\subsubsection{Equiprobabilidad de los miembros}

Toda la predicción probabilista trabaja con productos de SPC que se han construido partiendo de la base de que los miembros del SPC son equiprobables. Para el cómputo de las diferentes cantidades de interés a partir de la PDF estimada, como son la probabilidades, los percentiles, promedio, dispersión, etc., se confía en esta asunción básica: la hipótesis de equiprobabilidad de LAPLACE. Pero ¿son realmente equiprobables los miembros de un SPC? Por construcción y diseño de los propios SPC, así como por la experiencia del trabajo en modelos atmosféricos, pocas certezas hay al respecto, pero una cosa bien segura es que no todos los modelos se comportan o rinden igual según los días, según las situaciones atmosféricas. Ya venimos diciendo que la predecibilidad depende del flujo, y el comportamiento de los modelos también. Hay días en que unos modelos dan mejor resultado que otros y viceversa. En el fondo, este problema está relacionado con el anterior y no hay una respuesta teórica definitiva al problema. Se hace todo lo posible, en fase de diseño, para garantizar que todos los miembros tienen calidades equiparables, pero ¿equiprobabilidad? Aunque de momento es imposible asegurarlo, se trabaja asumiendo que la hay.

\subsection{Conclusiones}

Los modelos atmosféricos han mejorado enormemente en las últimas décadas, debido a los avances vertiginosos en supercomputación, satélites y asimilación de datos, entre otros factores. A pesar de ello, los modelos no son perfectos y fallan un número de días al año en un número de situaciones donde se pueden dar fenómenos extremos o fenómenos adversos, que siguen siendo un reto. Se hace necesario, pues, investigar en las fuentes de error de estos modelos y profundizar en la teoría en que se basan (cap. 17 en la página 257).

Los sistemas dinámicos con los que representamos la atmósfera tienen un carácter fuertemente no lineal, por lo que sufren sensibilidad a las variaciones en las condiciones iniciales, además de sensibilidad a la formulación del modelo, lo que pone un límite físico a su predecibilidad. Se hace necesario complementar a los modelos deterministas con simulaciones sobre las incertidumbres, introduciendo así modelos probabilistas. Pero la ecuación de FOKKER-PLANCK, que describe la evolución de la función densidad de probabilidad,
PDF, en el periodo de predicción no puede resolverse para los modelos atmosféricos, dado su elevado número de grados de libertad, en torno a $10^{8}-10^{9}$.

De modo que se utiliza una aproximación práctica para diseñar modelos probabilistas. Se muestrean los estados atmosféricos iniciales estimando una PDF inicial mediante un conjunto de estados plausibles compatibles con las observaciones, así como los diferentes aspectos y errores e incertidumbres de los modelos, con una diversidad de técnicas: multianálisis, multimodelo, perturbaciones, etc. Con el conjunto de estados atmosféricos previstos se construye la PDF prevista, concepción fundamental de la predicción probabilista.

Esta concepción se denomina sistema de predicción por conjuntos, SPC y las diferentes predicciones o estados previstos se denominan miembros del SPC. Así, los SPC son sistemas de predicción probabilistas de los que esperamos:

- Una estimación de la PDF del estado atmosférico.

- Diferentes escenarios atmosféricos.

- El promedio del SPC no es necesariamente una situación meteorológica, ni es el objetivo de la predicción probabilista.

- Información explícita, cuantitativa y detallada sobre la dispersión atmosférica, que está vinculada con la incertidumbre $\mathrm{y}$, por ende, con la predecibilidad.

- Predecibilidad dependiente del flujo, es decir, de la situación.

- Evaluar el potencial de fenómenos adversos y extremos, que no son exactamente los mismos. Esta información estará contenida en unos pocos miembros, a menudo en la cola de la PDF.

En AEMET, los predictores operativos comenzaron a familiarizarse con los SPC durante la década de los 90, en particular el llamado grupo de medio plazo, con el SPC del ECMWF, denominado ECENS. En esa época se utilizaba el ECENS para el medio plazo en las predicciones de escala más bien sinóptica, como apoyo al modelo determinista de mayor resolución ECHRES, asumiendo que la incertidumbre crece significativamente a partir del medio plazo, pero no en el corto.

De forma operativa y sistemática el ECENS empezó a utilizarse en el año 2 000, con una evaluación planificada de la dispersión, mediante grupos y supergrupos, con el uso metódico de mapas de probabilidad, etc. En cualquier caso, se siguió asumiendo durante un 
tiempo que la incertidumbre crece significativamente a partir del medio plazo, pero no en el corto. En las casi dos décadas de uso operativo, el ECENS ha mejorado notablemente, de modo que la dispersión y fiabilidad sinópticas habituales para una predicción D+4 de hace 15 años ha pasado hoy hasta una predicción D+7. Del mismo modo, hoy en día, podemos hacer predicciones para un $\mathrm{D}+4$ con una dispersión similar a la de un D+2 o, incluso, un D+1 de entonces.

Con la aparición de los SPC de corto plazo (e. g. AEMET-SREPS, cap. 21 en la página 313) se puede ir adoptando una concepción más fina: la incertidumbre crece significativamente o no dependiendo del flujo atmosférico de modo que, aunque a menudo empieza a ser significativa en el medio plazo, hay numerosas situaciones en que la incertidumbre es significativa desde un plazo muy temprano, sobre todo en las escalas kilométricas o convectivas, mesoescalares, con poco forzamiento sinóptico. Es decir, a día de hoy (2018) los SPC son herramientas útiles en todos los plazos de predicción. 


\subsection{Referencias}

[1] Anderson, J.L. L. "A Method for Producing and Evaluating Probabilistic Forecast from Ensemble Model Integration". En: Journal of climate 9.7 (1995), páginas 1518-1530. ISSN: 0894-8755. DOI: 10 . $1175 / 1520-0442(1996) 009<1518$ : AMFPAE > 2.0. CO; 2 (citado en página 175).

[2] Arribas, A, Robertson, K B y Mylne, K R. "Test of a poor man's ensemble prediction system for short-range probability forecasting". En: Monthly Weather Review 133.7 (2005), páginas 1825-1839 (citado en página 168).

[3] Berner, J. y col. "A Spectral Stochastic Kinetic Energy Backscatter Scheme and Its Impact on Flow-Dependent Predictability in the ECMWF Ensemble Prediction System". En: Journal of the Atmospheric Sciences 66.3 (mar. de 2009), páginas 603-626. ISSN: 00224928. DOI: $10.1175 / 2008$ JAS2677 . 1 (citado en página 175 ).

[4] Bishop, Craig H., Etherton, Brian J y MAJUMDAR, Sharanya J. "Adaptive sampling with the ensemble transform Kalman filter. Part I: Theoretical aspects". En: Monthly weather review 129.3 (2001), páginas 420-436 (citado en página 175).

[5] Bishop, Craig H. y Shanley, Kevin T. "Bayesian Model Averaging's Problematic Treatment of Extreme Weather and a Paradigm Shift That Fixes It". En: Monthly Weather Review 136.12 (2008), páginas 4641-4652. ISSN: 0027-0644. DOI: 10. 1175 / 2008MWR2565 . 1 (citado en página 190).

[6] Bonavita, Massimo y col. "EnKF and Hybrid Gain Ensemble Data Assimilation. Part II: EnKF and Hybrid Gain Results". En: Monthly Weather Review 143.12 (dic. de 2015), páginas 4865-4882. ISSN: 0027-0644. DOI: 10.1175/MWR-D-15-0071.1 (citado en página 175$)$.

[7] BuizzA, Roberto. "Potential forecast skill of ensemble prediction and spread and skill dis- tributions of the ECMWF ensemble prediction system". En: Monthly Weather Review 125.1 (1997), páginas 99-119. ISSN: 00270644. DOI: 10 . 1175/1520-0493(1997) 125<0099: PFSOEP>2 . 0 . CO ; 2 (citado en página 178).

[8] BuizzA, Roberto. "Chaos and weather prediction”. En: ECMWF Newsletter 12 (2002), páginas 1-7 (citado en página 178).

[9] BuizzA, Roberto, Miller, Martin J y PALMER, Tim N. "Stochastic representation of model uncertainties in the ECMWF ensemble prediction system". En: Quarterly Journal of the Royal Meteorological Society 125.560 (ago. de 1999), páginas 2887-2908. ISSN: 00359009. DOI: 10 . $1002 /$ qj . 49712556006 (citado en página 175).

[10] Buizza, Roberto y Palmer, Tim N. "The Singular-Vector Structure of the Atmospheric Global Circulation". En: Journal of the Atmospheric Sciences 52.9 (mayo de 1995), páginas 1434-1456. ISSN: 0022-4928. DOI: $10.1175 / 1520-0469$ (1995) 052<1434: TSVSOT > 2.0. CO 2 (citado en página 175).

[11] Callado, Alfons y col. "Ensemble Forecasting". En: Climate Change and Regional/Local Responses. Editado por RAY, Pallav. InTech, mayo de 2013. ISBN: 978-95351-1132-0. DOI: 10 . 5772/55699 (citado en páginas 178,188$)$.

[12] Casanova, S y Ahrens, B. "On the Weighting of Multimodel Ensembles in Seasonal and Short-Range Weather Forecasting". En: Monthly Weather Review 137.11 (2009), páginas 3811-3822. ISSN: 0027-0644, 1520-0493. DOI: 10 . 1175 / 2009mwr2893. 1 (citado en página 174).

[13] Dempster, Arthur P, Laird, Nan M y RuBIN, Donald B. "Maximum likelihood from incomplete data via the EM algorithm". En: Journal of the royal statistical society. Series B (methodological) (1977), páginas 1-38 (citado en página 190).

[14] Du, Jun. "Hybrid ensemble prediction system: a new ensembling approach". En: Pre- 
prints, Symposium on the 50th Anniversary of Operational Numerical Weather Prediction. 2004, páginas 14-17 (citado en página 175).

[15] EbERT, Elizabeth E. y EbERT, Elizabeth E. "Ability of a Poor Man's Ensemble to Predict the Probability and Distribution of Precipitation”. En: Monthly Weather Review 129.10 (oct. de 2001), páginas 2461-2480. ISSN: 0027-0644. DOI: 10 . $1175 / 1520-$ 0493 (2001) 129<2461: AOAPMS>2 . 0. CO; 2 (citado en página 168).

[16] Ebisuzaki, W y Kalnay, Eugenia. "Ensemble experiments with a new lagged average forecasting scheme". En: WMO Research Activities in Atmospheric and Oceanic Modeling Rep 15 (1991), página 308 (citado en página 174).

[17] Evans, R E y col. "Joint medium-range ensembles from the Met. Office and ECMWF systems". En: Monthly weather review 128.9 (2000), páginas 3104-3127. DOI: 10.1175/ 1520-0493 (2000) 128<3104: JMREFT >2. 0 . CO 2 (citado en página 175).

[18] Ferro, Christopher a. T. "Comparing Probabilistic Forecasting Systems with the Brier Score". En: Weather and Forecasting 22.5 (2007), páginas 1076-1088. ISSN: 08828156. DOI: 10.1175 /WAF1034 . 1 (citado en página 188 ).

[19] Fraley, Chris, Raftery, Adrian E. y Gneiting, Tilmann. "Calibrating Multimodel Forecast Ensembles with Exchangeable and Missing Members Using Bayesian Model Averaging". En: Monthly Weather Review 138.1 (2010), páginas 190-202. ISSN: 0027-0644. DOI: 10.1175/2009MWR3046 . 1 (citado en páginas 174, 175).

[20] García-Moya, José Antonio y col. "Predictability of short-range forecasting: A multimodel approach". En: Tellus, Series A: Dynamic Meteorology and Oceanography 63.3 (mayo de 2011), páginas 550-563. ISSN: 02806495. DOI: $10.1111 / \mathrm{j} \cdot 1600-0870$. 2010.00506. x (citado en páginas 174, 175, 178).
[21] Gneiting, Tilmann y col. "Calibrated probabilistic forecasting using ensemble model output statistics and minimum CRPS estimation”. En: Monthly Weather Review 133.5 (2005), páginas 1098-1118. ISSN: $0027-$ 0644. DOI: 10.1175 /MWR2904 . 1 (citado en página 175).

[22] Grimit, Eric P. y MASS, Clifford F. "Initial results of a mesoscale short-range ensemble forecasting system over the Pacific Northwest". En: Weather and Forecasting 17.2 (2002), páginas 192-205 (citado en página 175).

[23] Hagedorn, Renate y col. "Comparing TIGGE multimodel forecasts with reforecastcalibrated ECMWF ensemble forecasts". En: Quarterly Journal of the Royal Meteorological Society 138.668 (oct. de 2012), páginas 1814-1827. ISSN: 00359009. DOI: 10 . 1002/qj . 1895 (citado en página 174).

[24] Hamill, Thomas M. y Colucci, Stephen J. "Verification of Eta-RSM short-range ensemble forecasts". En: Monthly Weather Review 125.6 (1997), páginas 1312-1327 (citado en página 175).

[25] Hamill, Thomas M. y Colucci, Stephen J. "Evaluation of Eta-RSM Ensemble Probabilistic Precipitation Forecasts". En: Monthly Weather Review 126.3 (1998), páginas 711-724. ISSN: 0027-0644. DOI: 10 . 1175 / 1520 - 0493(1998) 126<0711: EOEREP>2 . 0 . CO; 2 (citado en página 175).

[26] Hamill, Thomas M., Snyder, Chris y Morss, Rebecca E. "A comparison of probabilistic forecasts from bred, singularvector, and perturbed observation ensembles". En: Monthly Weather Review 128.6 (2000), páginas 1835-1851 (citado en página 175).

[27] Hartmann, D. L., Buizza, Roberto y PALMeR, Tim N. "Singular Vectors: The Effect of Spatial Scale on Linear Growth of Disturbances". En: Journal of the Atmospheric Sciences 52.22 (nov. de 1995), páginas 3885-3894. ISSN: 0022-4928. DOI: 
$10.1175 / 1520-0469$ (1995) 052<3885: SVTEOS >2.0.CO;2 (citado en página 175).

[28] Hersbach, Hans. "Decomposition of the Continuous Ranked Probability Score for Ensemble Prediction Systems". En: Weather and Forecasting 15.5 (oct. de 2000), páginas 559-570. ISSN: 0882-8156. DOI: $10.1175 / 1520-0434(2000) 015<0559$ : DOTCRP> 2 . 0 . CO; 2 (citado en página 190).

[29] Hoeting, J. A. y col. "Bayesian Model Averaging: a tutorial". En: Statistical Sciences 14.4 (1999), páginas 382-417. ISSN: 08834237. DOI: $10.1214 / \mathrm{ss} / 1009212519$ (citado en página 190).

[30] Hoffman, Ross N y Kalnay, Eugenia. "Lagged average forecasting, an alternative to Monte Carlo forecasting". En: Tellus A 35.2 (1983), páginas 100-118. DOI: 10 . 3402/tellusa.v35i2 . 11425 (citado en página 174).

[31] Hollingsworth, A. "An experiment in Monte Carlo forecasting”. En: Proc. Workshop on Stochastic-Dynamic Forecasting. 1980, páginas 65-85 (citado en página 174).

[32] Hou, Dingchen, Kalnay, Eugenia y DroeGEMEIER, Kelvin K. "Objective verification of the SAMEX'98 ensemble forecasts". En: Monthly Weather Review 129.1 (2001), páginas 73-91 (citado en página 174).

[33] Houtekamer, Peter L. y Mitchell, Herschel L. "Data assimilation using an ensemble Kalman filter technique". En: Monthly Weather Review 126.3 (1998), páginas 796-811 (citado en página 175).

[34] Hunt, Brian R., Kostelich, Eric J. y SzUnYOGH, Istvan. "Efficient data assimilation for spatiotemporal chaos: A local ensemble transform Kalman filter". En: Physica D: Nonlinear Phenomena 230.1-2 (jun. de 2007), páginas 112-126. ISSN: 01672789. DOI: 10 . 1016/ J . PHYSD . 2006 . 11 . 008 (citado en página 175).

[35] IVERSEN, Trond y col. "Evaluation of 'GLAMEPS'-a proposed multimodel EPS for short range forecasting”. En: Tellus, Series A: Dynamic Meteorology and Oceanography 63.3 (mayo de 2011), páginas 513-530. ISSN: 02806495. DOI: 10 . 1111/j.1600-0870.2010.00507.x (citado en página 175 ).

[36] Jolliffe, Ian T. y Stephenson, David B. Forecast Verification: A Practitioner's Guide in Atmospheric Science. 2003, página 254. ISBN: 0470864419. DOI: $10.1016 /$ j.ijforecast. 2005.11.002 (citado en páginas 181, 190).

[37] Jones, Matthew S., Colle, Brian A. y Tongue, Jeffrey S. "Evaluation of a mesoscale short-range ensemble forecast system over the northeast United States". En: Weather and Forecasting 22.1 (2007), páginas 36-55 (citado en página 175).

[38] Kalnay, Eugenia. Atmospheric modeling, data assimilation and predictability. Cambridge university press, 2003 (citado en página 175).

[39] Kalnay, Eugenia y HaM, M. "Forecasting forecast skill in the Southern Hemisphere. Extended Abstracts." En: Extended Abstracts, Third Int. Conf. on Southern Hemisphere Meteorology and Oceanography, Buenos Aires, Argentina, Amer. Meteor. Soc. Volumen 2427. 1989, páginas 24-27 (citado en página 175).

[40] Krishnamurti, T N y col. "Improved weather and seasonal climate forecasts from multimodel superensemble". En: Science 285.5433 (1999), páginas 1548-1550 (citado en páginas 174,175$)$.

[41] LeITH, C E. "Theoretical skill of Monte Carlo forecasts". En: Monthly Weather Review 102.6 (1974), páginas 409-418 (citado en páginas 171, 174, 180).

[42] Lu, Chungu y col. "Short-Range Numerical Weather Prediction Using Time-Lagged Ensembles". En: Weather and Forecasting 22.3 (jun. de 2007), páginas 580-595. ISSN: 08828156. DOI: 10.1175/WAF999. 1 (citado en página 174). 
[43] Marsigli, C., Montani, A. y PaccagNELLA, T. "Perturbation of initial and boundary conditions for a limited-area ensemble: Multi-model versus single-model approach". En: Quarterly Journal of the Royal Meteorological Society 140.678 (abr. de 2014), páginas 197-208. ISSN: 1477870X. DOI: 10 . 1002/qj . 2128 (citado en página 175).

[44] Marsigli, C y col. "A strategy for highresolution ensemble prediction. II: Limitedarea experiments in four Alpine flood events". En: Quarterly Journal of the Royal Meteorological Society 127.576 (2001), páginas 2095-2115. DOI: 10 . 1002 / qj . 49712757613 (citado en página 175).

[45] MCLachlan, Geoffrey J y Krishnan, Thriyambakam. The EM algorithm and extensions. Volumen 382. John Wiley \& Sons, 2007, página 359. ISBN: 0471123587. DOI: 10.2307/1271189 (citado en página 190).

[46] Molteni, F. y col. "The ECMWF ensemble prediction system: Methodology and validation". En: Quarterly Journal of the Royal Meteorological Society 122.529 (ene. de 1996), páginas 73-119. ISSN: 1477-870X. DOI: 10 . 1002/ qj . 49712252905 (citado en páginas 173,175$)$.

[47] Molteni, F y col. "A strategy for highresolution ensemble prediction. I: Definition of representative members and globalmodel experiments". En: Quarterly Journal of the Royal Meteorological Society 127.576 (2001), páginas 2069-2094. DOI: 10.1002/ qj . 49712757612 (citado en página 175).

[48] Mullen, Steven L y Baumhefner, David P. "The impact of initial condition uncertainty on numerical simulations of large-scale explosive cyclogenesis". En: Monthly Weather Review 117.12 (1989), páginas 2800-2821 (citado en página 174).

[49] ORLANSKI, L. "A rational subdivision of scale for atmospheric processes". En: Bull. Amer. Meteor. Soc. 56 (1975), páginas 527-530 (citado en página 174).
[50] PALmer, T N y col. "Stochastic parametrization and model uncertainty". En: ECMWF Tech. Memo 598 (2009), páginas 1-42 (citado en página 175).

[51] Palmer, Tim N. y col. "Development of a European multimodel ensemble system for seasonal-to-interannual prediction (DEMETER)". En: Bulletin of the American Meteorological Society 85.6 (2004), páginas 853-872 (citado en páginas 174,175 ).

[52] Pellerin, G. y col. "Increasing the horizontal resolution of ensemble forecasts at CMC". En: Nonlinear processes in geophysics 10.6 (2003), páginas 463-468 (citado en página 173).

[53] Pendergrass, Angeline G y Elmore, Kimberly L. "Ensemble Forecast Bias Correction". En: 4th Annual Student Conference. Amer. Meteor. Soc., San Diego, CA P. 2004, páginas 1-19 (citado en página 174).

[54] Quiby, J y Denhard, M. “SRNWP-DWD poor-man ensemble prediction system: the PEPS project". En: Eumetnet Newsletter 8 (2003), páginas 9-12 (citado en página 168).

[55] RAfTery, Adrian E. y col. "Using Bayesian model averaging to calibrate forecast ensembles". En: Monthly Weather Review 133.5 (2005), páginas 1155-1174. ISSN: 0027-0644. DOI: 10.1175/MWR2906. 1 (citado en páginas 175,190$)$.

[56] Roche, Alexis. "EM algorithm and variants: An informal tutorial". En: arXiv preprint arXiv:1105.1476 (2011) (citado en página 190).

[57] SAITo, Kazuo y col. "Comparison of initial perturbation methods for the mesoscale ensemble prediction system of the Meteorological Research Institute for the WWRP Beijing 2008 Olympics Research and Development Project (B08RDP)". En: Tellus, Series A: Dynamic Meteorology and Oceanography 63.3 (mayo de 2011), páginas 445-467. ISSN: 02806495. DOI: $10.1111 / \mathrm{j} .1600-0870$. 2010.00509.x (citado en página 175). 
[58] Shutts, Glenn y Palmer, Tim N. "The use of high-resolution numerical simulations of tropical circulation to calibrate stochastic physics schemes". En: Proc. ECMWF Workshop Intra-Seasonal Variability. ECMWF Reading, UK. 2004, páginas 83-102 (citado en página 175).

[59] ShutTs, G y col. "Representing model uncertainty: Stochastic parametrizations at ECMWF". En: ECMWF Newsletter 129 (2011), páginas 19-24 (citado en página 175).

[60] Sloughter, J. McLean y col. "Probabilistic quantitative precipitation forecasting using Bayesian model averaging". En: Monthly Weather Review 135.9 (2007), páginas 3209-3220. ISSN: 0027-0644. DOI: 10 . 1175/MWR3441.1 (citado en página 175).

[61] Soltanzadeh, I., Azadi, M. y VaKiLI, G. A. "Using Bayesian Model Averaging (BMA) to calibrate probabilistic surface temperature forecasts over Iran". En: Annales Geophysicae 29.7 (jul. de 2011), páginas 1295-1303. ISSN: 09927689. DOI: 10. 5194/angeo-29-1295-2011 (citado en página 190).

[62] Stensrud, David J., BaO, J W y WarNER, T T. "Ensemble forecasting of mesoscale convective systems". En: Preprints, 12th Conf. on Numerical Weather Prediction, Phoenix, AZ, Amer. Meteor. Soc. 1998, páginas 265-268 (citado en página 175).

[63] StensRud, David J. y col. "Using ensembles for short-range forecasting". En: Monthly Weather Review 127.4 (1999), páginas 433-446 (citado en página 175).

[64] Stephenson, David B. y Doblas-Reyes, Francisco J. "Statistical methods for interpreting Monte Carlo ensemble forecasts". En: Tellus, Series A: Dynamic Meteorology and Oceanography 52.3 (2000), páginas 300-322. ISSN: 02806495. DOI: 10.3402/tellusa. v52i3.12267 (citado en página 174).

[65] Toth, Zoltan y KaLnAY, Eugenia. "Ensemble forecasting at NMC: The generation of perturbations". En: Bulletin of the american meteorological society 74.12 (1993), páginas 2317-2330 (citado en páginas 173, 175).

[66] Tотн, Zoltan y Kalnay, Eugenia. "Ensemble forecasting at NCEP and the breeding method". En: Monthly Weather Review 125.12 (1997), páginas 3297-3319 (citado en páginas $175,181,182)$.

[67] Tracton, M Steven y Kalnay, Eugenia. "Operational ensemble prediction at the $\mathrm{Na}$ tional Meteorological Center: Practical aspects". En: Weather and Forecasting 8.3 (1993), páginas 379-398 (citado en páginas 175,182$)$.

[68] Vich, M, Romero, R y Brooks, H E. "Ensemble prediction of Mediterranean highimpact events using potential vorticity perturbations. Part I: Comparison against the multiphysics approach". En: Atmospheric research 102.1 (2011), páginas 227-241 (citado en página 175).

[69] Vich, M, ROMERo, R y HOMAR, V. "Ensemble prediction of Mediterranean highimpact events using potential vorticity perturbations. Part II: adjoint-derived sensitivity zones". En: Atmospheric research 102.3 (2011), páginas 311-319 (citado en página 175).

[70] Wandishin, Matthew S y col. "Evaluation of a short-range multimodel ensemble system". En: Monthly Weather Review 129.4 (2001), páginas 729-747 (citado en página 175).

[71] WILKs, Daniel S. Statistical Methods in the Atmospheric Sciences. Academic Press, 2011, página 676. ISBN: 9780123850225. URL: https : / / www . sciencedirect . com / bookseries / international geophysics / vol / 100 (citado en páginas 181, 190).

[72] Wobus, Richard L y KaLnay, Eugenia. "Three years of operational prediction of forecast skill at NMC". En: Monthly weather review 123.7 (1995), páginas 2132-2148 (citado en página 175). 